\title{
Odor-Induced Multi-Level Inhibitory Maps in Drosophila
}

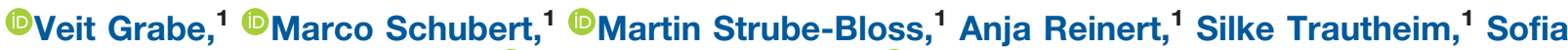 \\ Lavista-Llanos, ${ }^{1}$ André Fiala, ${ }^{2}{ }^{\circledR}$ Bill S. Hansson, ${ }^{1}$ and ${ }^{\circledR}$ Silke Sachse ${ }^{1}$
}

https://doi.org/10.1523/ENEURO.0213-19.2019

${ }^{1}$ Department of Evolutionary Neuroethology, Max Planck Institute for Chemical Ecology, Jena 07745, Germany and

${ }^{2}$ Department of Molecular Neurobiology of Behavior, Johann-Friedrich-Blumenbach-Institute for Zoology and

Anthropology, University of Göttingen, Göttingen 37077, Germany

\begin{abstract}
Optical imaging of intracellular $\mathrm{Ca}^{2+}$ influx as a correlate of neuronal excitation represents a standard technique for visualizing spatiotemporal activity of neuronal networks. However, the information-processing properties of single neurons and neuronal circuits likewise involve inhibition of neuronal membrane potential. Here, we report spatially resolved optical imaging of odor-evoked inhibitory patterns in the olfactory circuitry of Drosophila using a genetically encoded fluorescent $\mathrm{Cl}^{-}$sensor. In combination with the excitatory component reflected by intracellular $\mathrm{Ca}^{2+}$ dynamics, we present a comprehensive functional map of both odor-evoked neuronal activation and inhibition at different levels of olfactory processing. We demonstrate that odor-evoked inhibition carried by $\mathrm{Cl}^{-}$influx is present both in sensory neurons and second-order projection neurons (PNs), and is characterized by stereotypic, odor-specific patterns. $\mathrm{Cl}^{-}$-mediated inhibition features distinct dynamics in different neuronal populations. Our data support a dual role of inhibitory neurons in the olfactory system: global gain control across the neuronal circuitry and glomerulus-specific inhibition to enhance neuronal information processing.
\end{abstract}

Key words: antennal lobe; chloride imaging; Drosophila; inhibition; olfactory coding; sensory processing

\section{Significance Statement}

Neural inhibition is evidently as important as excitation given it is present at every level of sensory processing. This study characterizes odor-evoked inhibitory patterns along different levels of olfactory processing of Drosophila using functional imaging via Clomeleon, a genetically encoded indicator for chloride ions, the main mediator of synaptic inhibition in mature neurons. In combination with the excitatory component reflected by intracellular calcium, we analyzed the interplay between odor-evoked excitation and inhibition. Our data provide both a more accurate and comprehensive characterization of the actual information content encoded by the olfactory circuitry, as well as elucidate network properties within the primary olfactory center of the fly.

\section{Introduction}

Inhibition of neural excitability is a ubiquitous feature of all neuronal circuits. Neurons that release inhibitory transmitters are present in all parts of the nervous system. In the olfactory systems of both insects and vertebrates,

Received June 5, 2019; accepted December 16, 2019; First published December 20, 2019.

The authors declare no competing financial interests.

Author contributions: V.G., B.S.H., and S.S. designed research; V.G., M.S., A.R., S.T., A.F., and S.S. performed research; V.G., M.S., M.S.-B., A.R., inhibition is crucial for stimulus gain control (Olsen and Wilson, 2008; Root et al., 2008), synchronizing neural networks (Laurent et al., 2001), generating precise timing (Schoppa and Westbrook, 1999; Margrie and Schaefer, 2003), broadening transmission of olfactory signals (Nagel

S.L.-L., A.F., and S.S. analyzed data; V.G., M.S., M.S.-B., A.R., A.F., B.S.H., and S.S. wrote the paper.

This work was supported by a Federal Ministry of Education and Research (BMBF) grant (S.S., V.G., M.S.-B., A.R. and S.T.), by the Max Planck Society, and by German Research Foundation Grants SPP1392 Fl-3-1 and SA 909/3-1, 
et al., 2015), odor mixture interactions (Mohamed et al., 2019), and enhancing contrast between similar odor representations (Mori et al., 1999; Sachse and Galizia, 2002; Urban, 2002). In the mammalian olfactory bulb, inhibition is largely mediated by dendrodendritic synaptic connections between excitatory mitral cells and inhibitory granule cells (Schoppa and Urban, 2003; Egger and Urban, 2006). Despite these important roles of inhibition for odor processing, most studies analyzing olfactory coding at the level of spatially distributed neuronal populations focused on monitoring neuronal excitation. Therefore, odor representations at the level of the insect antennal lobe (AL) or the vertebrate olfactory bulb typically have been characterized as patterns of excitation. Here, we aimed at monitoring spatially distributed maps of odor-evoked inhibition at different levels of processing in Drosophila melanogaster.

In the fly, odors are detected by olfactory sensory neurons (OSNs) located on the antennae and maxillary palps. Each OSN typically expresses one or very few chemo-receptor genes, and each OSN projects its axon to the $A L$, the insect analog of the vertebrate olfactory bulb. In the AL, those OSNs expressing the same odorant receptor (OR) stereotypically converge to the same spatially invariant olfactory glomeruli (Couto et al., 2005; Fishilevich and Vosshall, 2005), each of which can be unambiguously identified (Laissue et al., 1999; Grabe et al., 2015). The AL is densely innervated by local interneurons (LNs) that mediate both intraglomerular and transglomerular inhibition (Wilson and Laurent, 2005; Seki et al., 2010). Olfactory projection neurons (PNs) convey the olfactory signals to higher-order brain centers.

The morphologic structure of the AL network specifies the physiologic logic of how odors are encoded: Each odorant evokes a characteristic, spatiotemporal activity pattern leading to a combinatorial, stereotypic activation of glomeruli in the AL (Fiala et al., 2002; Wang et al., 2003). Inhibitory LNs provide both feedforward synaptic inhibition of PNs and feedback inhibition of OSNs (Wilson and

\section{3-2 (A.F. and S.S.).}

Acknowledgements: We thank Sonja Bisch-Knaden for statistical advice; Mathias Ditzen for programming tools in IDL; Walton Jones and Leslie B. Vosshall for help with generating UAS-Clomeleon flies; Thomas Kuner for helpful advice regarding Clomeleon imaging; Erich Buchner and Thomas Völler for assistance with the initial establishment of chloride imaging; Thomas Kuner, Andreas Schäfer, and Marcus Stensmyr for thoughtful comments on this manuscript; and Michelle Wibraham and Andrew Davis for editorial assistance.

M. Schubert's present address: Freie Universität Berlin, Department of Biology, Chemistry and Pharmacy, Institute of Biology-Neurobiology, Berlin 14195, Germany.

M. Strube-Bloss's present address: Department of Biological Cybernetics, Faculty of Biology, University of Bielefeld, Universitätsstr, 25, Bielefeld 33615, Germany.

A. Reinert's present address: Institute of Anatomy, Histology and Embryology, Faculty of Veterinary Medicine, Leipzig University, an den Tierkliniken 43, Leipzig 04103, Germany.

Correspondence should be addressed to Silke Sachse at ssachse@ice.mpg.de.

https://doi.org/10.1523/ENEURO.0213-19.2019

Copyright $\odot 2020$ Grabe et al.

This is an open-access article distributed under the terms of the Creative Commons Attribution 4.0 International license, which permits unrestricted use, distribution and reproduction in any medium provided that the original work is properly attributed.
Mainen, 2006; Olsen and Wilson, 2008; Root et al., 2008). However, it still remains elusive how spatially distributed, odor-evoked inhibition interferes with and relates to the well-described excitation-based odor maps.

In Drosophila, functional imaging has mainly relied on genetically expressed $\mathrm{Ca}^{2+}$ sensors that detect intracellular $\mathrm{Ca}^{2+}$ dynamics as a correlate of neuronal excitation (Grienberger and Konnerth, 2012). In this study, we monitored odor-induced inhibitory maps in the olfactory circuitry using a DNA-encoded indicator for $\mathrm{Cl}^{-}$, the main ionic mediator of synaptic inhibition in mature neurons (Owens and Kriegstein, 2002). The FRET-based indicator Clomeleon consists of a $\mathrm{Cl}^{-}$-sensitive yellow fluorescent protein (YFP) and a $\mathrm{Cl}^{-}$-insensitive cyan fluorescent protein (CFP; Kuner and Augustine, 2000). Binding of $\mathrm{Cl}^{-}$to YFP reduces its absorbance, which results in a change of the YFP/CFP emission ratio proportional to $\left[\mathrm{Cl}^{-}\right]_{i}$. The applicability of Clomeleon in vivo has been demonstrated in hippocampal slices (Berglund et al., 2006), retinal bipolar cells (Haverkamp et al., 2005; Duebel et al., 2006), thalamo-cortical neurons of mice (Glykys et al., 2009) and cerebellar granule cells (Berglund et al., 2016).

We genetically expressed Clomeleon in defined olfactory neurons and characterized odor-evoked inhibition at different levels of olfactory processing in comparison with $\mathrm{Ca}^{2+}$-mediated activity using the likewise FRET-based $\mathrm{Ca}^{2+}$-sensitive protein Cameleon 2.1 (Miyawaki et al., 1999). First, we observed odor-evoked $\mathrm{Cl}^{-}$-influx in dendrites of OSNs. Second, we generated a comprehensive functional map of both odor-evoked activation and inhibition of the fly AL. We demonstrate that odor-evoked inhibition carried by $\mathrm{Cl}^{-}$influx is characterized by stereotypic odor-specific patterns. Third, we show that $\mathrm{Cl}^{-}$mediated inhibition exhibits distinct features at different levels of olfactory processing pointing toward multiple roles of inhibition in the olfactory system.

\section{Materials and Methods}

\section{Drosophila stocks and in vivo preparation}

All fly stocks were maintained on conventional cornmeal-agar-molasses medium under $12 / 12$ h light/ dark conditions, relative humidity of $70 \%$ and at $25^{\circ} \mathrm{C}$. The Clomeleon DNA construct (Kuner and Augustine, 2000), kindly provided by Thomas Kuner, was inserted into the pUAST vector (Brand and Perrimon, 1993) via the EcoRI and Xhol restriction sites. Transgenic constructs were injected by Genetic Services Inc. into yw embryos using standard procedures and single transformants were outcrossed to autosomal balancers for chromosomal mapping. Two independent insertions on different chromosomes were combined. Homozygous female flies, 6-10 d old, carrying four copies of the UAS:Clomeleon transgenes, were used for all imaging experiments. The fly strain UAS-Cameleon 2.1 (Fiala et al., 2002) was chosen for monitoring odor-evoked $\mathrm{Ca}^{2+}$ signals as an appropriate FRET-based sensor comparable in its chromophores with Clomeleon. Orco-Gal4 (RRID:BDSC_23292; Wang et al., 2003), Or22a-Gal4 (RRID:BDSC_9951; Vosshall et al., 2000), and GH146-Gal4 (RRID:BDSC_30026; 
Stocker et al., 1997) were used to drive expression of UAS-Clomeleon or UAS-Cameleon (RRID:BDSC_6901).

\section{Optical imaging}

For imaging intracellular $\mathrm{Cl}^{-}$and $\mathrm{Ca}^{2+}$ dynamics in the $\mathrm{AL}$, flies were restrained in custom-built holders and a small window was cut into the head capsule. The hole was covered with physiologic saline solution, and imaging was performed using a water immersion objective directly positioned above the exposed brain. Pharmaca [GABA, potassium gluconate (KGlu), PTX, 5-nitro-2(-3-phenylpropylamine) benzoic acid (NPPB)] were applied by exchanging the saline drop on the brain by a drop of the approximate volume and the targeted concentration. For NPPB an additional ethanol application was conducted to control for the solvent effect (data not shown). For transcuticular antennal imaging, flies were restrained as for the in vivo dissection method without opening the head capsule. Or22aexpressing OSNs were imaged from the posterior side of the antenna, while the majority of OSNs using Orco-Gal4 were recorded from the anterior side.

Imaging experiments were performed using TillPhotonics imaging equipment (TILL imago, Till Photonics $\mathrm{GmbH}$ ) with a CCD-camera (PCO imaging, Sensicam) and a fluorescence microscope (Olympus, BX51WI) equipped with a $20 \times$ water immersion objective (NA 0.95, XLUM Plan FI, Olympus) for AL imaging and a 10× air objective (NA 0.30, UPlan FLN, Olympus) for antennal imaging. A monochromator (Polychrome V, Till Photonics) provided light at 440 $\mathrm{nm}$ excitation wavelength which was guided through a 470-nm dichroic short pass filter. The beam-splitter (Optical Insights, DV-CC) separated YFP from CFP emission with a 505 DCXR and narrowed the emissions with bandpass filters of $535 / 30 \mathrm{~nm}$ for YFP and $465 / 30 \mathrm{~nm}$ for CFP. Images of both emitted wavelengths were projected side by side onto a single CCD camera chip (PCO Imaging, Sensicam). Fourfold binning on the CCD-camera chip resulted in an image size of $344 \times 260$ pixels with one pixel corresponding to $1.25 \times 1.25 \mu \mathrm{m}$. Each recording lasted for $20 \mathrm{~s}$ with an acquisition rate of $2 \mathrm{~Hz}$. Since Clomeleon yielded a very low signal-to-noise ratio, we had to apply long exposure times which limited our recording frequency. We also performed experiments with the usually used frequency of $4 \mathrm{~Hz}$, resulting in weaker signal intensities and a lower dynamic range. Since these signals did not reveal different temporal patterns in the odor-evoked responses as the slower recorded signals, we decided in favor of an increased signal-to-noise ratio and maintained a recording frequency of $2 \mathrm{~Hz}$ for the whole study. Odors were applied $2 \mathrm{~s}$ after experiment onset and lasted for $2 \mathrm{~s}$. Individual flies were imaged for up to $1 \mathrm{~h}$, with interstimulus time intervals of $1-3 \mathrm{~min}$.

\section{Odor stimulation}

Pure odorants were diluted in mineral oil (BioChemika Ultra; odor CAS: ethyl-3-hydroxybuytrate: 5405-41-4, benzaldehyde: 100-52-7, acetic acid: 64-19-7, cis-vaccenylacetate: 6186-98-7, pentyl acetate: 628-63-7, 1-hexanol: 11127-3, ethyl benzoate: 93-89-0). For use, $6 \mu$ of 1:10 diluted odor was pipetted onto a small piece of filter paper (100 $\mathrm{mm}^{2}$, Whatman), which was inserted into a glass Pasteur pipette. A stimulus controller (Syntech, Stimulus Controller CS-55) was used to apply the odor into a continuous airstream at $1 \mathrm{l} / \mathrm{min}$, monitored by a flow meter (Cole Parmer). An acrylic glass tube guided the airflow to the fly antennae. Two additional air sources (airflow $0.5 \mathrm{l} / \mathrm{min}$ ) were connected to the tube and the stimulus controller. One of them consisted of the glass pipette containing the odor on filter paper and was hooked up for odor application, whereas the other pipette was empty and added clean air to the continuous airstream forming an air equation which was switched off during odor application.

\section{Data analysis}

Data were analyzed using custom-written IDL software (ITT Visual Information Solutions). First, a rigid registration was accomplished for all recordings separately to minimize movement artifacts throughout the time series. Second, the ratio of the two fluorescent signals was calculated as $F_{Y F P} / F_{C F P}$ for every time point. The ratio $(R)$ represents the relative magnitude of the signal intensity. To achieve a comparable standard for the calculation of the relative fluorescence changes of the ratio $(\Delta R / R)$, the fluorescence background was subtracted from the averaged values of frames $0-5$ in each measurement, such that baseline fluorescence was normalized to zero. The false color-coded fluorescence changes in the raw-data images were calculated as the delta of frame 5 and 30 (Clomeleon) and frame 5 and 15 (Cameleon). Specific time traces of a measurement depict the mean of a $7 \times 7$-pixel coordinate (i.e., $9 \times 9 \mu \mathrm{m}$ ), which was positioned into an anatomically identified glomerulus and plotted as a function over time. Since GH146-Ga/4 does not label glomeruli VM5d and VM5v, these could not be characterized at the PN level (Grabe et al., 2015). To generate schematic AL maps, the mean value of frames 10-30 for Clomeleon and 10-15 for Cameleon of a specific glomerulus and odor was averaged over all animals imaged. Although the chloride and calcium kinetics are clearly odor induced, they develop very slowly over time and show their maximal response change after odor offset. We therefore selected a delayed time window for our signal evaluation to capture the maximum/minimum of the odor-induced responses. One has to keep in mind that the monitored $\mathrm{Ca}^{2+}$ and $\mathrm{Cl}^{-}$ dynamics are also dependent on the kinetics and concentrations (i.e., expression levels) of the fluorescent sensors and might not reflect accurately the physiologic time traces. However, this issue is more relevant for fast stimulus dynamics (Martelli and Fiala, 2019), while with regard to slow recording frequencies, as used here, the resulting kinetics of $\mathrm{Cl}^{-}$and $\mathrm{Ca}^{2+}$ binding are rather negligible.

Responses in each fly were normalized to the highest $\mathrm{Cl}^{-}$or $\mathrm{Ca}^{2+}$ signal in each animal over all odors. To extract the temporal aspect of odor separation in the different neuronal populations, Euclidean distances (L2-Norm) were calculated. To compare the results, we always used the same set of 11 identified glomeruli in each data set. For a given stimulus $a$, the n-dimensional population vector $\left(v^{2}\right)$ was constructed using the relative fluorescence changes over time. Then the population vectors of two stimuli, $a$ and $b$, were used to calculated the distance for 
every single data point (time) in the 40 frames as follows: $d(t)=\left(\Sigma\left(v_{i}^{a}(t)-v_{i}^{b}(t)\right)^{2}\right)^{1 / 2}$, where $i$ is an index for the i-th glomerulus. In addition to the Euclidean distances, principal component analysis was used to visualize the population activity of OSNs and PNs depending on the imaged reporter protein. Population vectors of all odor stimulations were aligned, taking into account time as the source of sample points, and number of glomeruli as the dimension of the original component space using the MATLAB statistical toolbox. All statistical analyses were performed using GraphPad InStat 3 as specified in each figure legend.

\section{Results}

\section{Clomeleon as an indicator of intracellular $\mathrm{Cl}^{-}$ dynamics in olfactory neurons}

We generated flies carrying the genetically encoded $\mathrm{Cl}^{-}$ sensor Clomeleon (Kuner and Augustine, 2000) to visualize in vivo $\mathrm{Cl}^{-}$-mediated inhibitory responses in the olfactory system. Using the binary GAL4-UAS transcriptional system (Brand and Perrimon, 1993), we expressed Clomeleon in the majority of OSNs using Orco-Gal4 (Wang et al., 2003) and in PNs using GH146-Gal4 (Stocker et al., 1997; Fig. 1A,B). To test whether Clomeleon is functional in Drosophila olfactory neurons, we optically monitored fluorescence changes in OSNs and PNs in the AL, while we applied KGlu to induce neuronal excitation globally and, concomitantly, inhibition through LN input onto OSNs and PNs (Fig. 1C-F; see network scheme in Fig. 2A). Applying KGlu increased CFP fluorescence, while YFP fluorescence was strongly decreased; thereby, the YFP/CFP ratio was reduced. To verify that this reflected inhibition, we applied the inhibitory transmitter GABA. GABA application immediately reduced the YFP/CFP ratio in both OSNs and PNs (Fig. 1G,H). Notably, we observed a second, strong emission decrease which was delayed by $\sim 35 \mathrm{~s}$. The source of this second decrease is yet unclear, but could be due to the slow diffusion rate of GABA as it is bath applied to the whole brain and not actively perfused. The gradually increasing GABA concentration might surpass a threshold that initiates a strong inhibition reflected by the second phase. In combination with a gradual desensitization toward GABA (Hong and Wilson, 2015), this could explain the observed slow and biphasic GABA effect. To confirm that these ratio changes were dependent on $\mathrm{Cl}^{-}$, we removed $\mathrm{Cl}^{-}$from the saline solution covering the fly's brain. Odor application before $\mathrm{Cl}^{-}$removal induced a clear ratio change, which was significantly reduced using $\mathrm{Cl}^{-}$-free saline (Fig. 1/). To further verify that our reporter was reflecting the intracellular $\mathrm{Cl}^{-}$concentration, we applied the chloride channel blocker NPPB to block $\mathrm{Cl}^{-}$channels in Drosophila neurons (O'Donnell et al., 1998). As expected, application of NPPB strongly reduced the $\mathrm{Cl}^{-}$influx which was partly reversibly (Fig. 1J).

Since the YFP fluorescence has been reported to be affected by the $\mathrm{pH}$ value at $\left[\mathrm{Cl}^{-}\right]_{\mathrm{i}}$ above $50 \mathrm{mM}$ (Kuner and Augustine, 2000), we verified that the fluorescence emission was not influenced by $\mathrm{pH}$ changes within the physiologically relevant range of $6.9-7.3$ (Fig. $1 \mathrm{~K}$ ). This is in accordance with the described $\left[\mathrm{Cl}^{-}\right]_{\mathrm{i}}$ in OSNs, which is $\sim 24 \mathrm{mM}$ in moths (Steinbrecht, 1992) and $\sim 20 \mathrm{mM}$ in flies (Reinert et al., 2011). Therefore, a potential influence of $\mathrm{pH}$ changes on Clomeleon is negligible. Overall, our results confirm that Clomeleon functions reliably as a $\mathrm{Cl}^{-}$indicator in olfactory neurons of the Drosophila AL.

\section{Odor stimulation induces peripheral $\mathrm{Cl}^{-}$influx in dendrites of OSNs}

Next, we analyzed whether odor stimulation causes a $\mathrm{Cl}^{-}$increase at the most peripheral level of sensory transduction and performed transcuticular $\mathrm{Cl}^{-}$imaging in $\mathrm{OSN}$ dendrites located on the fly's antenna (Fig. $2 A, B$ ). Odor stimulation induced an odor-specific, spatially confined increase in $\left[\mathrm{Cl}^{-}\right]_{\mathrm{i}}$. These spatially restricted signals correspond to distinct sensillum types, which have welldescribed, specific distributions on the third antennal segment (Shanbhag et al., 1999; Grabe et al., 2016; Fig. $2 C, D$ ). To determine which sensillum types were excited by the odors used, we performed $\mathrm{Ca}^{2+}$ imaging in comparison using the ratiometric $\mathrm{Ca}^{2+}$ indicator Cameleon 2.1 (Miyawaki et al., 1999). $\mathrm{Cl}^{-}$signals are characterized by a reduction in the Clomeleon's YFP/CFP ratio (= increase in $\left[\mathrm{Cl}^{-}\right]_{\mathrm{i}}$ ), whereas $\mathrm{Ca}^{2+}$ signals are indicated by a ratio increase in the Cameleon's YFP/CFP ratio (= increase in $\left[\mathrm{Ca}^{2+}\right]_{\mathrm{i}}$; Fig. 2D). Notably, some odors, such as ethyl-3hydroxybutyrate, evoked both a $\mathrm{Ca}^{2+}$ and a $\mathrm{Cl}^{-}$signal in the same areas of the antennal surface, indicating a concomitant $\mathrm{Ca}^{2+}$ and $\mathrm{Cl}^{-}$influx in OSNs. Other odorants, e.g., benzaldehyde, induced spatially non-overlapping $\mathrm{Cl}^{-}$ and $\mathrm{Ca}^{2+}$ signals, indicating independent excitation and inhibition events in distinct sensilla (Fig. 2D). This separation of inhibition and excitation is underlined by the strong $\mathrm{Cl}^{-}$increase induced by acetic acid in the tip region of the antenna without significant $\mathrm{Ca}^{2+}$ responses (Fig. 2E). Acetic acid activates solely OSNs present in one type of coeloconic sensilla (Abuin et al., 2011), which is not labeled by the Orco-Gal4 line. To verify that the observed antennal $\mathrm{Cl}^{-}$signals indeed reflect neuronal inhibition, we expressed Clomeleon selectively in OSNs expressing Or47b. OSNs expressing this receptor selectively respond to the pheromone methyl laurate and are mainly inhibited by other odors (Hallem and Carlson, 2006; Dweck et al., 2015). Application of the odor ethyl-3-hydroxybutyrate, which induces an inhibition of Or47b-expressing OSNs as shown via single-sensillum recordings (Hallem and Carlson, 2006), leads to a strong and long-lasting $\mathrm{Cl}^{-}$influx in this OSN type (Fig. 2F).

We next wondered whether the odor-induced antennal $\mathrm{Cl}^{-}$increase derives within the sensillum and can be attributed to OSN dendrites or whether these signals rather reflect a feedback inhibition from the AL. We therefore monitored $\mathrm{Cl}^{-}$signals following odor stimulation while we abolished any feedback signaling from the AL by cutting the antennal nerve (Fig. 2G). Interestingly, this treatment significantly reduced $\mathrm{Cl}^{-}$signals in the antenna, but did not abolish them. This result demonstrates $\mathrm{Cl}^{-}$conductivity in dendrites of OSNs, indicating that $\mathrm{Cl}^{-}$channels are present in OSNs and localized to the most peripheral dendritic compartments in the fly antenna. However, at 
A
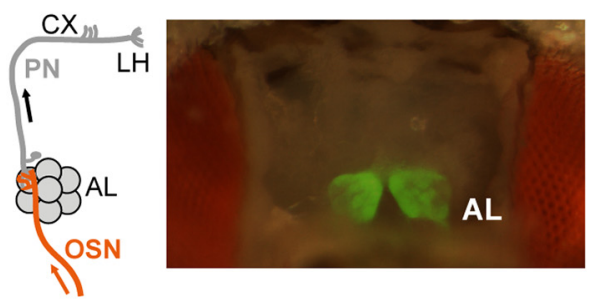

C

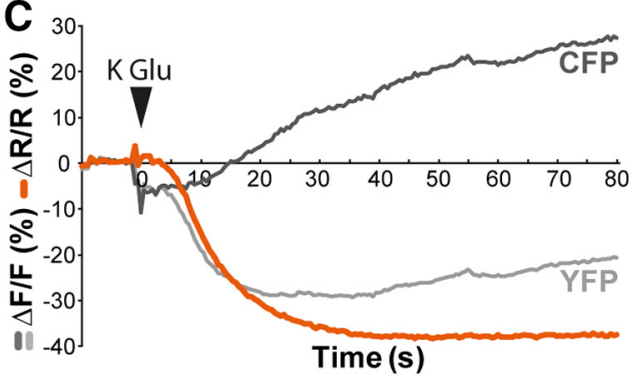

E

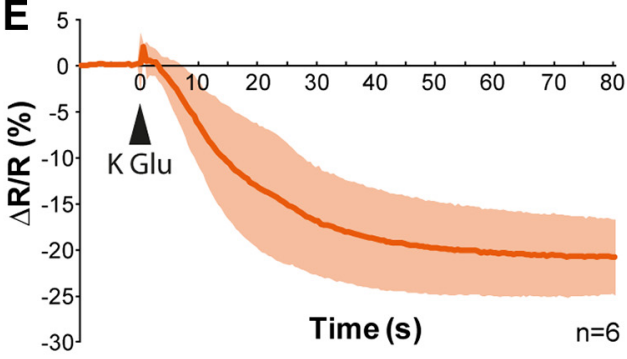

G

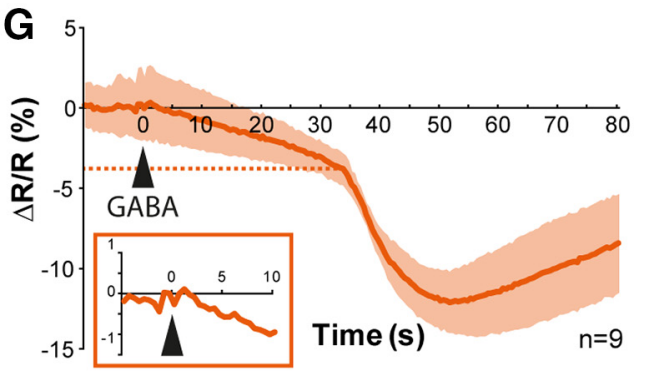

B

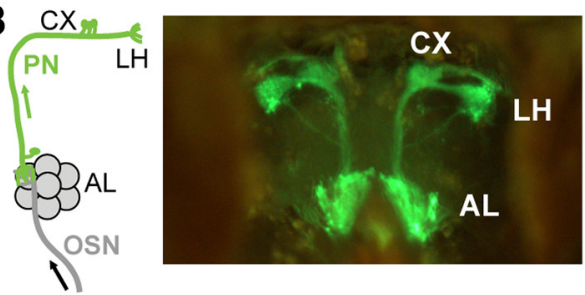

D

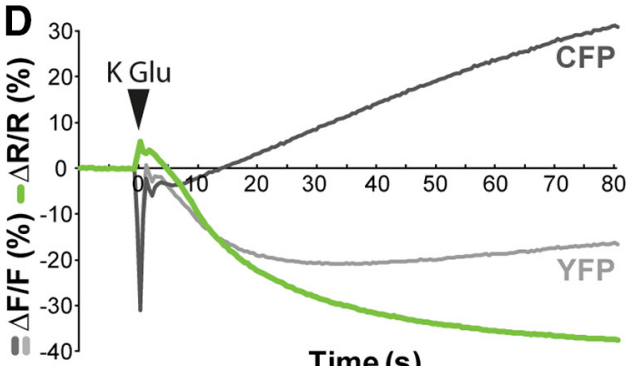

Time (s)
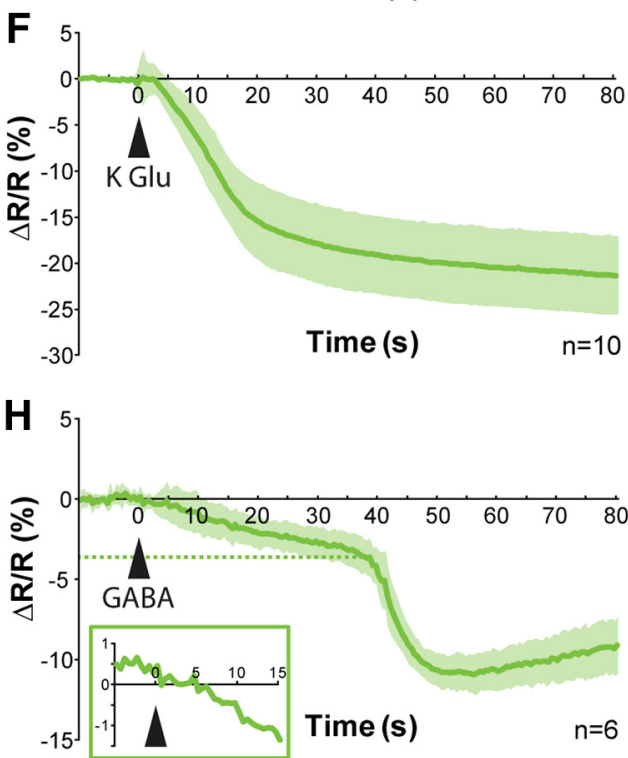
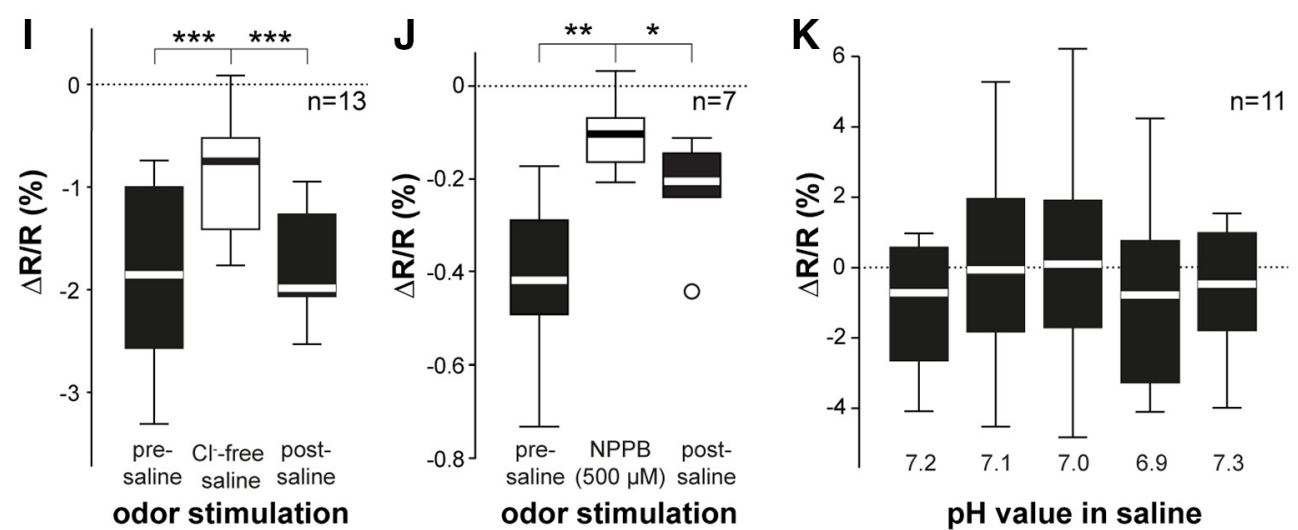

Figure 1. Clomeleon is a functional chloride indicator in Drosophila olfactory neurons. $\boldsymbol{A}, \boldsymbol{B}$, Schematic of AL neurons indicating expression site of Clomeleon with images of brain preparation showing Clomeleon YFP baseline fluorescence $(\boldsymbol{A}, \mathrm{OSNs}$; $\boldsymbol{B}$, PNs). AL, antennal lobe; CX, calyx; LH, lateral horn. $\boldsymbol{C}, \boldsymbol{D}$, Fluorescence change in a representative animal over time of CFP, YFP, and YFP:CFP ratio induced by KGlu application $(1 \mathrm{M}, 20 \mu \mathrm{l})$ into saline $(300 \mu \mathrm{l})$ in OSNs $(\boldsymbol{C})$ and PNs $(\boldsymbol{D})$. $\boldsymbol{E}$, $\boldsymbol{F}$, Time course of $\left[\mathrm{Cl}^{-}\right]_{\mathrm{i}}$ increase induced by applying KGlu (arrowhead) averaged across several animals in OSNs $(\boldsymbol{E})$ and PNs $(\boldsymbol{F})$. Color shading indicates SD, $n=6-10$. G, $\boldsymbol{H}$, Time courses of $\left[\mathrm{Cl}^{-}\right]_{\mathrm{i}}$ increase induced by GABA application $(1 \mathrm{M}, 20 \mu \mathrm{l})$ into saline $(300 \mu \mathrm{l})$ averaged across several animals in OSNs $(\mathbf{G})$ and PNs $(\boldsymbol{H})$. Insets show enlarged area around the time point of GABA application. Dashed lines mark the biphasic response threshold. Color shading indicates SD, $n=6-9$. I, Effect of $\mathrm{Cl}^{-}$free saline application on $\mathrm{Cl}^{-}$changes evoked by 
continued

ethyl-3-hydroxybutyrate in OSNs. Box plots represent median value (horizontal line inside the box), interquartile range (box), and minimum/maximum value (whiskers). Removing $\mathrm{Cl}^{-}$significantly reduced the Clomeleon signal $(* * * p<0.001$, repeated measures ANOVA, $n=13)$. $\boldsymbol{J}$, Effect of chloride channel blocker NPPB $(500 \mu \mathrm{M})$ application on $\mathrm{Cl}^{-}$signals evoked by ethyl-3-hydroxybutyrate in OSNs ( $* * p<0.01, * p<0.05$, repeated measures ANOVA, $n=7)$. $K$, Quantification of Clomeleon baseline fluorescence in OSNs at different saline $\mathrm{pH}$ in relation to standard condition (i.e., $\mathrm{pH}$ 7.3). Arrangement of different box plots from left to right reflects temporal sequence of the experiment $(p=0.144$, repeated measures ANOVA, $n=11)$.

the same time we do not exclude an additional feedback inhibition from the AL.

\section{$\mathrm{Cl}^{-}$-dependent, inhibitory odor maps in OSN terminals in the $\mathrm{AL}$}

Within the AL, OSNs are presynaptically inhibited by GABAergic LNs (Olsen and Wilson, 2008; Root et al., 2008; Mohamed et al., 2019) with varying and glomerulusspecific GABA sensitivities (Hong and Wilson, 2015). To visualize odor-evoked inhibition at the level of the axonal termini across multiple glomeruli, we performed $\mathrm{Cl}^{-}$imaging in presynaptic OSN axons in the AL using an in vivo preparation (Strutz et al., 2012; Fig. 3A). Due to the stereotypy of the glomerular AL morphology, we could reliably identify individual glomeruli in each animal using digital AL atlases (Laissue et al., 1999; Grabe et al., 2015; Fig. 3B). Each odor stimulation induced a specific combinatorial pattern of inhibited glomeruli, which was stereotypic among individuals (Figs. $3 C$ ). The time courses of YFP/CFP ratio changes in selected glomeruli revealed an odor- and glomerulus-specific $\mathrm{Cl}^{-}$influx (Fig. 3D). However, a time-resolved analysis across multiple glomeruli showed that $\mathrm{Cl}^{-}$signals are detected in all glomeruli optically accessible during the imaging experiments (Fig. $3 E$ ). In conclusion, strong and odor-specific inhibition of distinct glomeruli is accompanied by less intense, global inhibition across the entire OSN population. The $\mathrm{Cl}^{-}$signals that were optically monitored lasted until the end of each measurement, i.e., they strongly outlasted the 2-s odor stimulation. Therefore, we examined how much time was required before the Clomeleon signal returned to baseline (Fig. 3F-H). Odor application with different interstimulus intervals revealed that although the fluorescence emission $(\Delta R / R)$ continued to drop after stimulation, repetitive odor stimulation still elicited further Clomeleon signals after 10 or $60 \mathrm{~s}$ (Fig. 3F,G). A complete recovery of the Clomeleon fluorescence was not observed before 120 $s$ after odor stimulation had elapsed (Fig. 3H). The actual kinetics of any fluorescence sensor depend on multiple factors, e.g., the concentration of the sensor determined by the expression level, the affinity of the sensor to its ligand, or the dynamic range of the sensor. Therefore, it is difficult to conclude to what degree the dynamics of $\mathrm{Cl}^{-}$ transients quantitatively reflect the actual balance between $\mathrm{Cl}^{-}$influx and intracellular $\mathrm{Cl}^{-}$removal. However, a slow recovery of Clomeleon signals has also been observed in mammalian neurons (Kuner and Augustine, 2000; Berglund et al., 2006) and has been attributed to the slow removal of $\left[\mathrm{Cl}^{-}\right]_{\mathrm{i}}$ by transporters rather than kinetic properties of the $\mathrm{Cl}^{-}$sensor (Staley and Proctor, 1999; Berglund et al., 2009, 2016). It is therefore quite conceiv- able that the odor-evoked $\mathrm{Cl}$ - transients in OSNs indeed strongly outlast the actual stimulation.

\section{Comparison between odor-evoked $\mathrm{Cl}^{-}$signaling in OSN dendrites and axons}

As shown so far, odors induce a clear $\mathrm{Cl}^{-}$increase at the level of the peripheral signal input, i.e., in the antenna (Fig. 2), and at the sites of synaptic transmission, i.e., in OSNs of the AL (Fig. 3). To examine the relationship between these two signal sources in more detail, we comparatively monitored odor-evoked $\left[\mathrm{Cl}^{-}\right]_{i}$ and $\left[\mathrm{Ca}^{2+}\right]_{i}$ of a single OSN population at its dendrites and axonal termini. This was achieved by selective expression of Clomeleon or Cameleon, respectively, in OSNs expressing Or22a, which targets the glomerulus DM2 (Couto et al., 2005; Fishilevich and Vosshall, 2005). As described previously (Pelz et al., 2006), a strong $\mathrm{Ca}^{2+}$ response was elicited by methyl hexanoate, while ethyl-3hydroxybutyrate induced an intermediate, and benzaldehyde no significant response (Fig. 4A,B). The relative intensities of odor-evoked $\mathrm{Ca}^{2+}$ responses did not differ between antenna and AL (Fig. 4C). However, all three odors induced comparatively strong $\mathrm{Cl}^{-}$responses in the fly antenna (Fig. $4 A$, lower panel), while only methyl hexanoate, one of the most potent activators of this OSN type, elicited a significant $\mathrm{Cl}^{-}$response at the $\mathrm{AL}$ level (Fig. 4B, lower panel, $D$ ). Hence, the intensity of odor-evoked $\mathrm{Cl}^{-}$influx at the level of OSN dendrites and somata is relatively independent of the actual intensity of the accompanying $\mathrm{Ca}^{2+}$ influx. On the contrary $\mathrm{Cl}^{-}$-mediated inhibition in the $\mathrm{AL}$ reflects more odor-specific inhibition.

\section{$\mathrm{Cl}^{-}$-dependent, inhibitory odor maps in PN dendrites in the $A L$}

To analyze inhibitory patterns of output neurons in the $\mathrm{AL}$, we performed $\mathrm{Cl}^{-}$imaging at the dendrites of PNs using the enhancer trap line GH146-Gal4 that labels the majority of uniglomerular PNs (Stocker et al., 1997). Odor application induced clear spatially confined and odorantspecific patterns of inhibition that could be assigned to identified glomeruli (Fig. 5A,B). A time-resolved analysis across all glomeruli revealed a strongly pronounced $\mathrm{Cl}^{-}$ influx in a glomerulus- and odor-specific manner, and typically with some delay after odor onset (Fig. 5C). These odor-specific, inhibitory patterns evolve slowly over time and persist until the end of the measurement, as it is the case at the OSN level. Notably, we observed a concordance in the $\mathrm{Cl}^{-}$responses between OSNs and PNs, in a way that a given odor inhibited the same glomeruli at the input and the output level of the AL (Figs. $3 E, 5 C$ ). However, this correlation was only apparent for strongly inhib- 
A

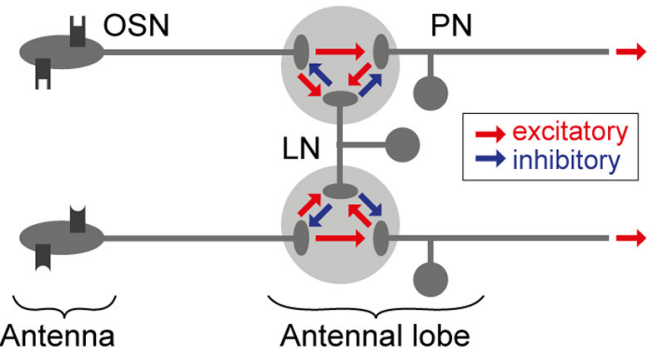

B

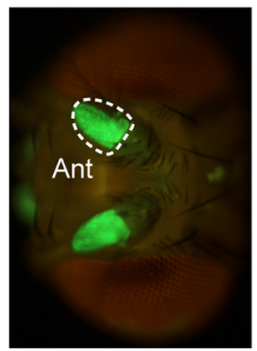

C

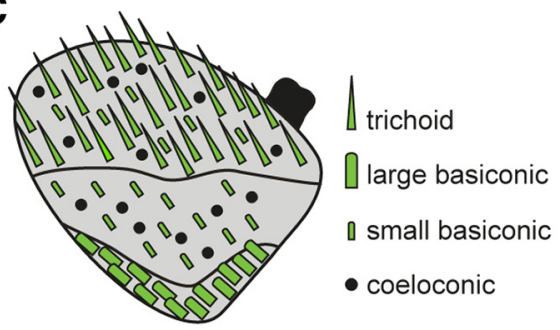

D
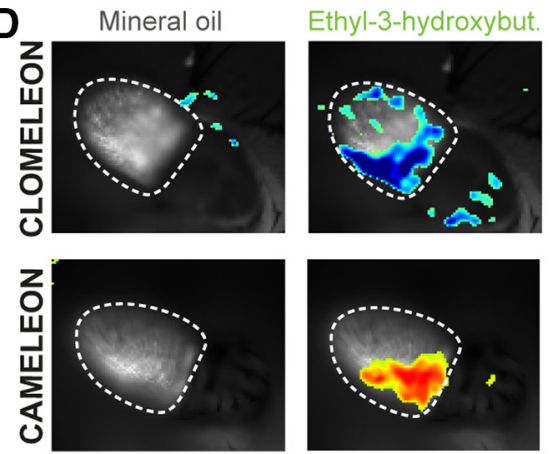

Benzaldehyde
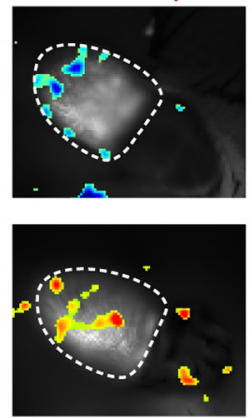
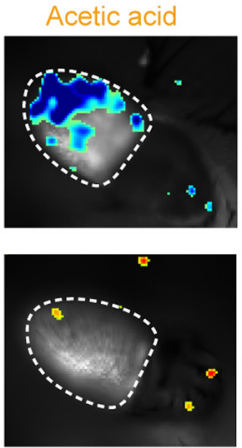

F
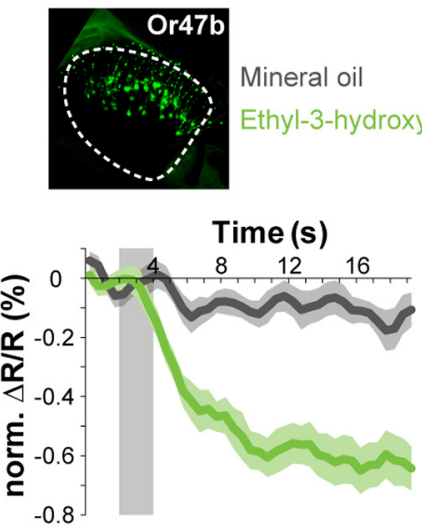

r47b

Mineral oil

Ethyl-3-hydroxybut.
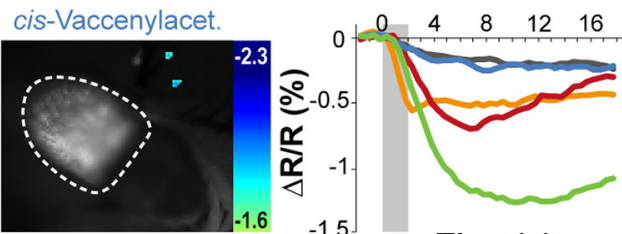

Time (s)
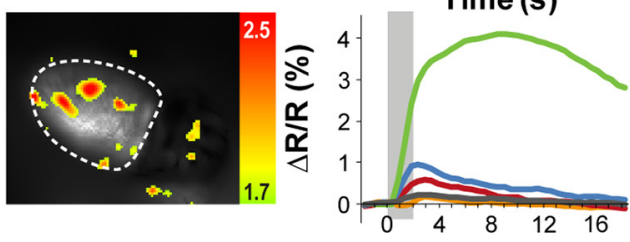

G
E

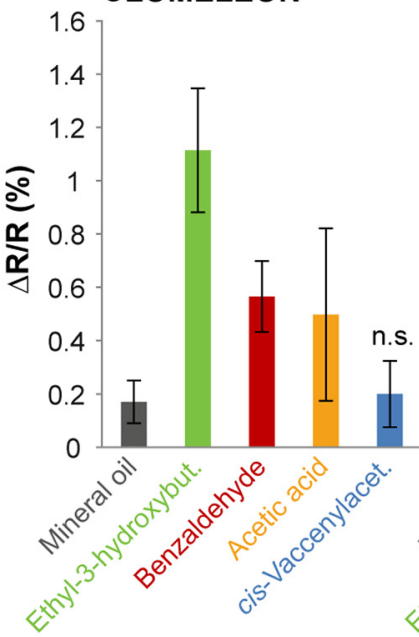

CAMELEON

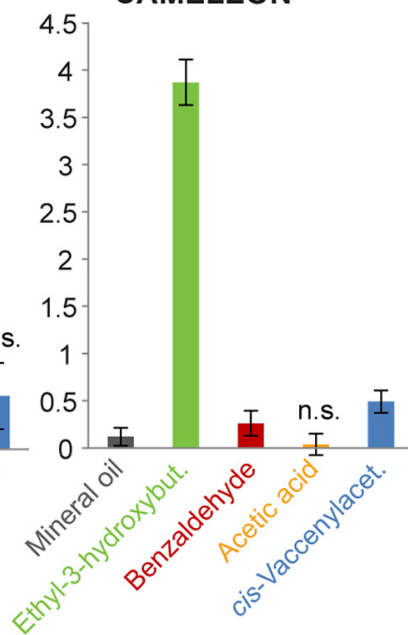

\section{Antenna}

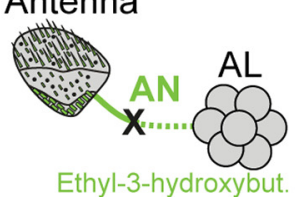

Ethyl-3-hydroxybut.

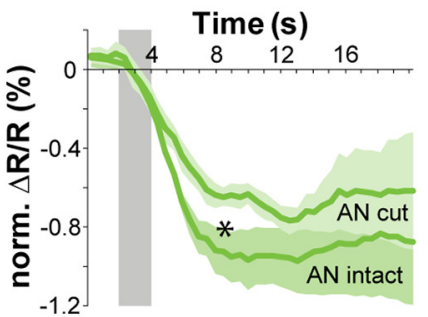

Figure 2. Odor application induces spatially confined chloride influx in OSNs in the Drosophila antenna. $\boldsymbol{A}$, Network model scheme of neuronal connectivity in the fly AL. B, Clomeleon YFP baseline fluorescence in OSN dendrites in the Drosophila antenna (Ant). $\boldsymbol{C}$, Schematic of olfactory sensilla distribution on the third antennal segment. Sensilla marked in green are labeled by Orco-Gal4. $\boldsymbol{D}$, Pseudocolor rendering of odor-evoked changes in $\mathrm{Cl}^{-}$concentration using Clomeleon (upper row) and in $\mathrm{Ca}^{2+}$ concentration using Cameleon (lower row) in response to different odors and mineral oil in OSN in the antenna. Images represent $\Delta \mathrm{R} / \mathrm{R}$ (\%) superimposed onto raw fluorescence images according to the scales and color codes on the right. Time courses on the right reveal representative $\mathrm{Cl}^{-}$and $\mathrm{Ca}^{2+}$ signals for different odors across the entire antennal segment. Odor application is indicated by a gray bar. $\boldsymbol{E}$, Quantification of $\mathrm{Cl}^{-}$(left) and $\mathrm{Ca}^{2+}$ (right) responses to different odors and mineral oil (n.s., not significant from solvent; repeated measures ANOVA followed by Dunnett multiple comparisons test, $n=8$ ). $\boldsymbol{F}$, Maximum intensity projection of Clomeleon expressed in the antenna under the control of Or47b-Gal4. Time courses of normalized $\mathrm{Cl}^{-}$responses to the solvent control mineral oil and ethyl-3-hydroxybutyrate $(n=8)$. $\mathbf{G}$, Schematic of the connection between the antenna and AL via the antennal nerve (AN), which was disrupted here. Time course of normalized $\mathrm{Cl}^{-}$responses to ethyl-3-hydroxybutyrate in three animals of the left antenna (AN intact, solid line) and right antenna after the right AN was cut (AN cut, dotted line). Lines indicate means, color shading gives SEM ( $* p<0.05$, two-way ANOVA).

ited glomeruli, while weaker $\mathrm{Cl}^{-}$responses occurred in more glomeruli at the PN level when compared to OSNs. Again, this indicates a dual role of $\mathrm{Cl}^{-}$-mediated inhibition, i.e., a moderate, global inhibition and a strong odor- and glomerulus-specific inhibition, potentially reflecting the various types of inhibitory neurons in the $A L$, the global and patchy GABAergic LNs (Chou et al., 2010; Mohamed et al., 2019). 
A

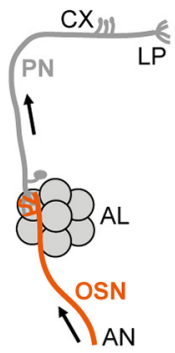

B

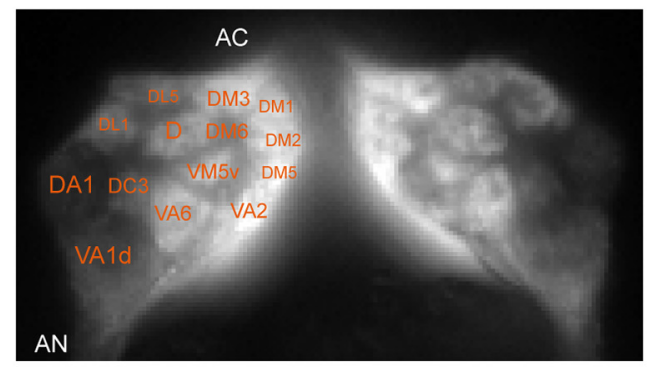

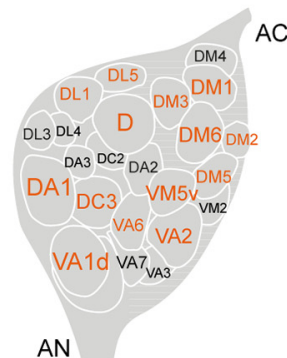

Ethyl benzoate
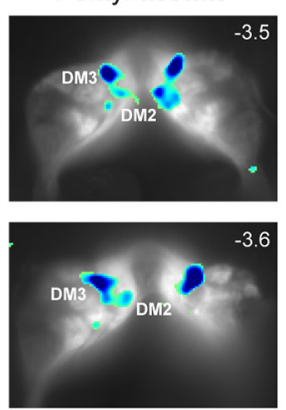
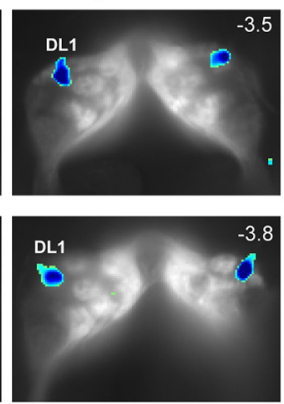
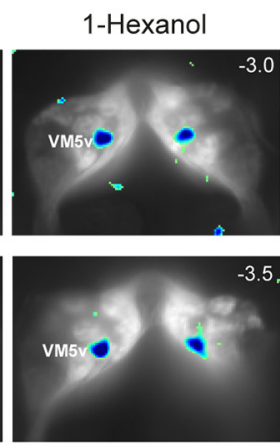

Ethyl-3-hydroxybut.
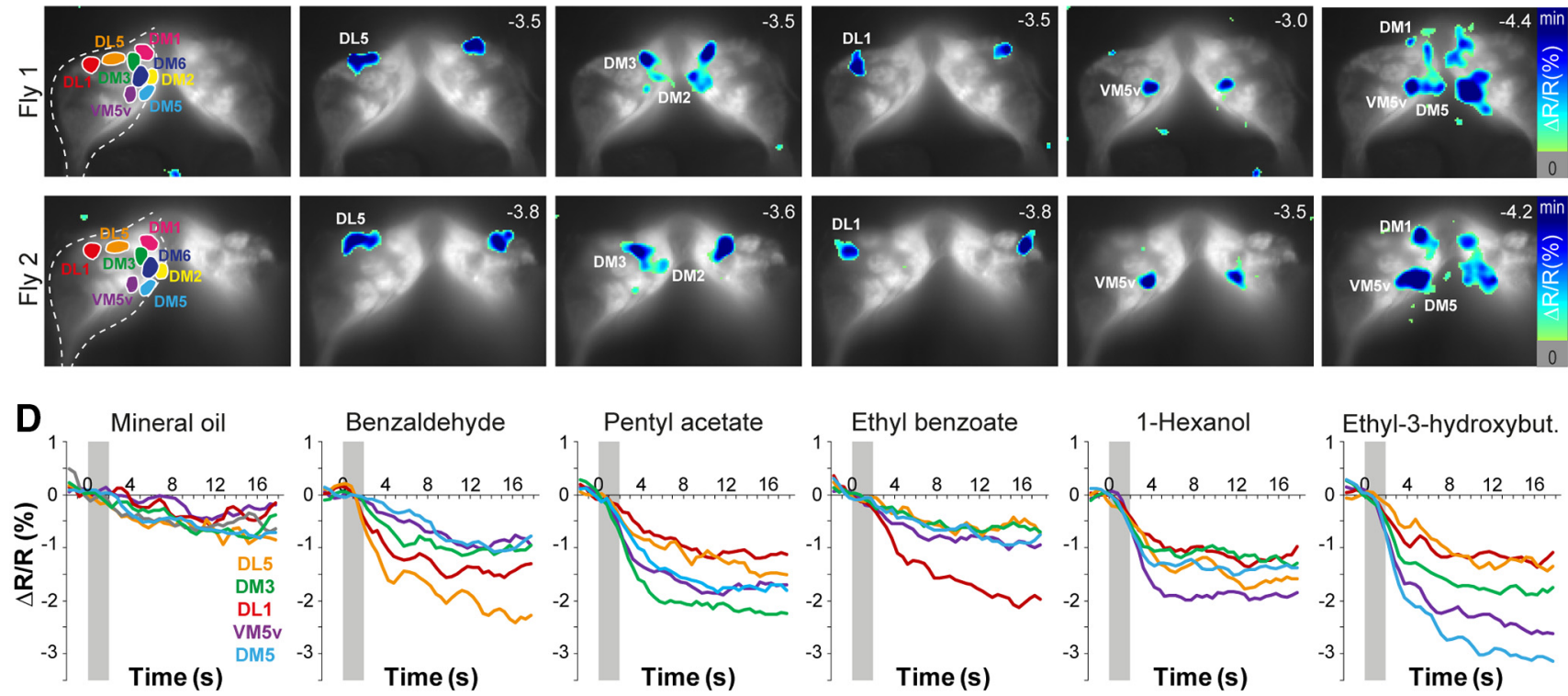

Benzaldehyde

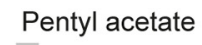

Ethyl benzoate

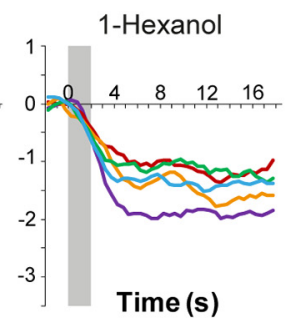

Ethyl-3-hydroxybut.

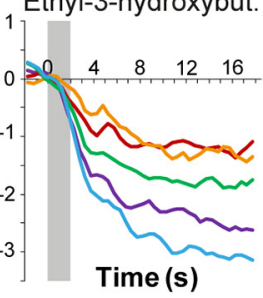

Time (s)
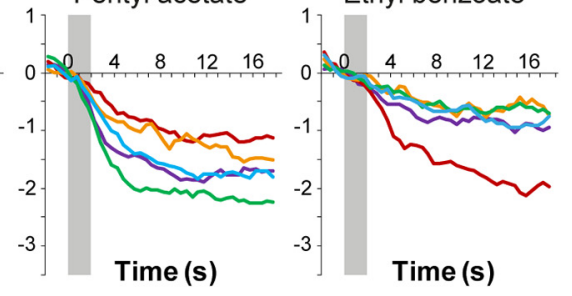

Time (s)

Time (s)
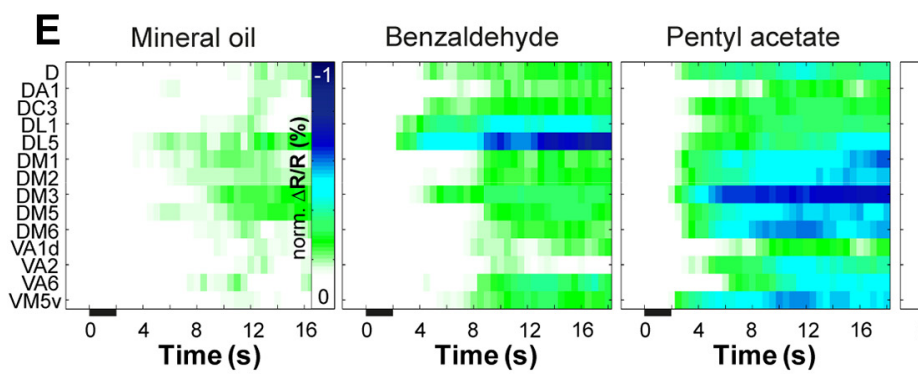

Ethyl benzoate

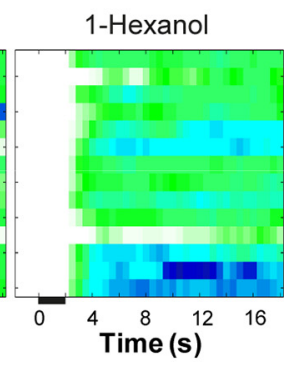

Ethyl-3-hydroxybut.
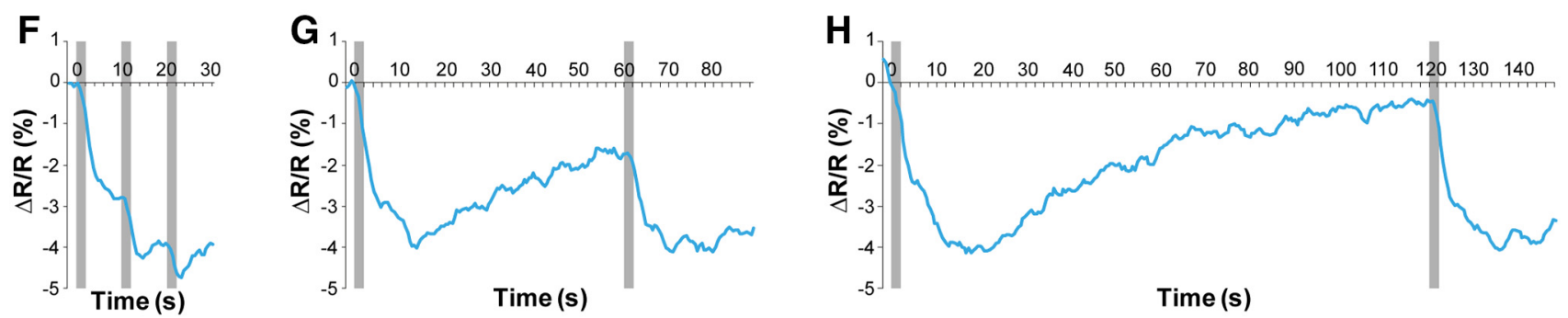

Figure 3. An odor-specific spatial map of chloride responses in AL sensory neurons. $\boldsymbol{A}$, Schematic illustrating the expression site of Clomeleon (AL, antennal lobe; AN, antennal nerve; CX, calyx; LP, lateral protocerebrum). $\boldsymbol{B}$, left, Clomeleon YFP baseline fluorescence in axon termini of OSNs in the AL with anatomic identification of individual glomeruli. Right, Schematic AL map viewed from the angle used for imaging experiments. Glomeruli marked in orange could reliably be identified. AC, antennal commissure. C, Pseudocolor rendering of $\mathrm{Cl}^{-}$responses to different odors and mineral oil in OSN axon termini in the AL of two different individuals. Images represent $\Delta \mathrm{R} / \mathrm{R}(\%)$ superimposed onto raw fluorescence images according to the scales on the right. Numbers in each image represent individual fluorescence minimum. Glomerular positions are shown in the first image; glomeruli revealing highest $\mathrm{Cl}^{-}$increase are indicated in each image. The minimum of the scaling is given in each frame in the upper right corner. $\boldsymbol{D}$, Time courses of $\mathrm{Cl}^{-}$influx for each odor and mineral oil averaged across six to nine animals. Individual glomeruli are indicated by different colors, odor 


\section{continued}

stimulation is marked in gray. $\boldsymbol{E}$, False color pictures of averaged odor-evoked $\mathrm{Cl}^{-}$signals for $14 \mathrm{glomeruli}$ ( $42 \%$ of all glomeruli labeled by Orco-Gal4) over time across six to nine animals. Clomeleon responses were normalized to highest $\mathrm{Cl}^{-}$influx in each animal over all odors before averaging. Black bar indicates odor application. $\boldsymbol{F}-\boldsymbol{H}$, Representative time courses of $\mathrm{Cl}^{-}$influx to repeated stimulations of ethyl-3-hydroxybutyrate using interstimulus intervals of $10 \mathrm{~s}(\boldsymbol{F}), 60 \mathrm{~s}(\boldsymbol{G})$, and $120 \mathrm{~s}(\boldsymbol{H})$. Odor stimulations are marked in gray.

Since the spatiotemporal activity of PN ensembles is influenced by inhibitory, GABAergic LNs (Wilson and Laurent, 2005), we tested whether the Clomeleon signals were dependent on GABA receptors. Therefore, we performed $\mathrm{Cl}^{-}$imaging experiments after silencing the inhibitory $\mathrm{LN}$ input by applying the $\mathrm{GABA}_{\mathrm{A}}$-type antagonist picrotoxin $(5 \mu \mathrm{M})$ that blocks ionotropic $\mathrm{Cl}^{-}$-ion channels. In addition to $\mathrm{GABA}_{\mathrm{A}}$ receptors, picrotoxin has been shown to block also glutamate-gated chloride channels (GluCl; Liu and Wilson, 2013). However, at the low concentration used in this study the antagonist mainly functions as a $\mathrm{GABA}_{\mathrm{A}}$ antagonist without affecting $\mathrm{GluCl}$ channels (Hong and Wilson, 2015). Application of picrotoxin led to a significant reduction of the odor-induced $\mathrm{Cl}^{-}$ signals by on average 59\% (Fig. 5D). This result indicates that the $\mathrm{GABA}_{\mathrm{A}}$ receptor contributes to the $\mathrm{Cl}^{-}$-mediated inhibition at the AL output level.

\section{A comparative functional map of odor-evoked activation and inhibition in the AL}

We next examined the overlap of the odor-evoked inhibitory patterns compared to the spatial patterns of glomerular $\mathrm{Ca}^{2+}$ activities. To do so, we performed functional imaging experiments to a variety of different odors and monitored odor-evoked $\mathrm{Ca}^{2+}$ as well as $\mathrm{Cl}^{-}$responses by expressing Cameleon or Clomeleon in OSNs and PNs, respectively. Subsequently, we mapped the odor-induced responses to identified glomeruli to generate a functional $\mathrm{AL}$ atlas (Fig. 6). First, we observed that, in the majority of cases, the odorevoked maps of excitation and inhibition closely match at the input and the output level, i.e., those glomeruli which were excited were also often inhibited by a certain odor. Such a concordance suggests a gain control mechanism for odor-induced excitation as described for the OSN level (OIsen and Wilson, 2008), which should occur in all glomeruli receiving an excitatory input. Second, we observed that some glomeruli were inhibited without being excited. This finding suggests a second role of $\mathrm{Cl}^{-}$-mediated inhibition in the Drosophila AL which could contribute to confining the spatiotemporal patterns, resulting in an enhanced contrast between different odor representations as shown for the honeybee AL (Sachse and Galizia, 2002). Notably, we never observed glomeruli, which were excited without being inhibited.

\section{Input-output transformation}

Last, we analyzed the difference between the odorevoked representations of input and output neurons for a subgroup of 11 glomeruli that could be unambiguously identified in each experiment (Fig. 7A). Since each fluorescent reporter protein exhibits different kinetics, one has to be careful when comparing temporal dynamics between different sensors. We therefore compared tem- poral aspects of odor-evoked responses of different processing levels for one reporter protein only. Quantification of the evoked mean responses to specific odors showed that excitatory as well as inhibitory odor responses were, on average, stronger at the PN level than at the OSN level (Fig. 7B) which is well in line with electrophysiological recordings (Wilson and Laurent, 2005; Bhandawat et al., 2007; Seki et al., 2017). To visualize how the odor-specific responses evolve over time, we applied principal component analyses to reduce the multidimensional, spatiotemporal activity/inhibition to three dimensions and illustrated the odor-evoked ensemble activity as trajectories over time (Fig. 7C). Independent of the reporter protein, different odors evoked distinct trajectories, which demonstrate an odor-specific separation of $\mathrm{Ca}^{2+}$ as well as $\mathrm{Cl}^{-}$ responses at both processing levels, i.e., OSNs and PNs. To quantify how fast this odor separation evolved, we calculated Euclidean distances between the population vectors of the different odor representations for Cameleon and Clomeleon signals, respectively (Fig. $7 D, E$, upper panels). Interestingly, $\mathrm{PN}$ responses revealed in general lower Euclidean distances than OSN responses. Although PNs showed an increased level of inhibition, they also exhibited generally broader odorevoked responses compared to OSNs (Wilson et al., 2004; Seki et al., 2017). This broadening leads to wider odor tuning curves and a stronger overlap of odor representations at the PN level (Niewalda et al., 2011; Schubert et al., 2014; Seki et al., 2017), while PN responses show a higher degree of odor categorization according to behaviorally meaningful values (Niewalda et al., 2011; Knaden et al., 2012).

After normalizing all pair-wise Euclidean distances, we calculated the latencies to the half maximum odor separation (Fig. $7 D, E$, lower panel) and observed that it was reached significantly earlier in PNs than in OSNs. This finding is in accordance with electrophysiological recordings in Drosophila showing that PN responses have shorter latencies to reach $90 \%$ of their response peak than OSNs (Bhandawat et al., 2007) indicating that PNs act as high-pass filters that rapidly convey rising OSN responses to third-order neurons. When considering the Clomeleon responses, this latency shift is even more pronounced for $\mathrm{Cl}^{-}$signals. This observation is most likely due to reciprocal inhibitory mechanisms that differently affect OSN and PN responses: PNs are inhibited by fast forward inhibition from OSNs via GABAergic LNs (Wilson and Laurent, 2005) before OSNs receive presynaptic feedback inhibition from PNs through, in turn, GABAergic LNs (Olsen and Wilson, 2008; Root et al., 2008). 
A

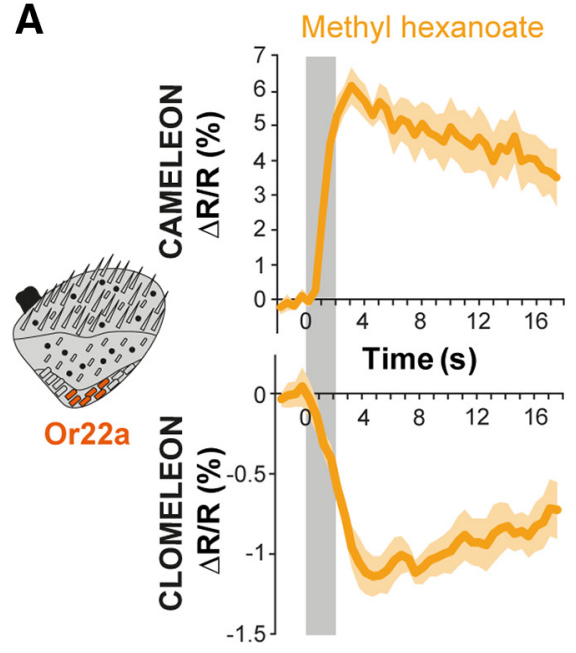

B

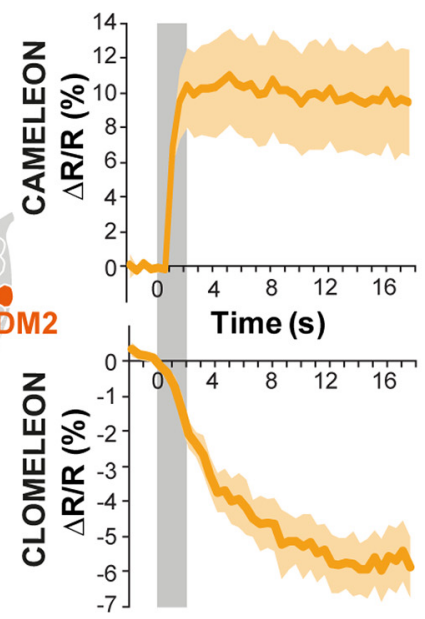

C

CAMELEON

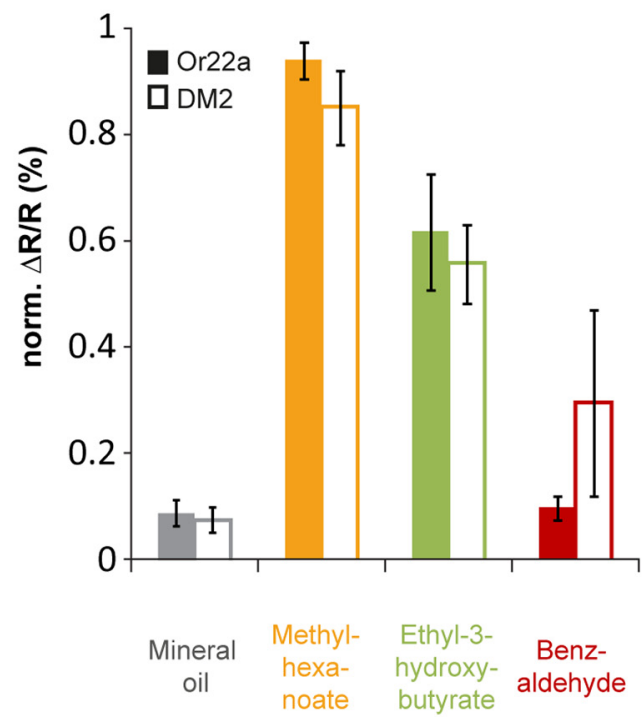

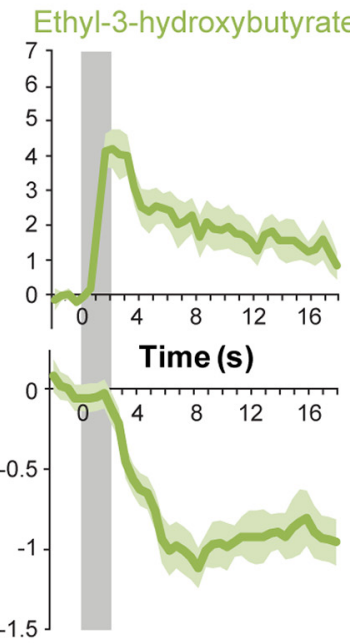
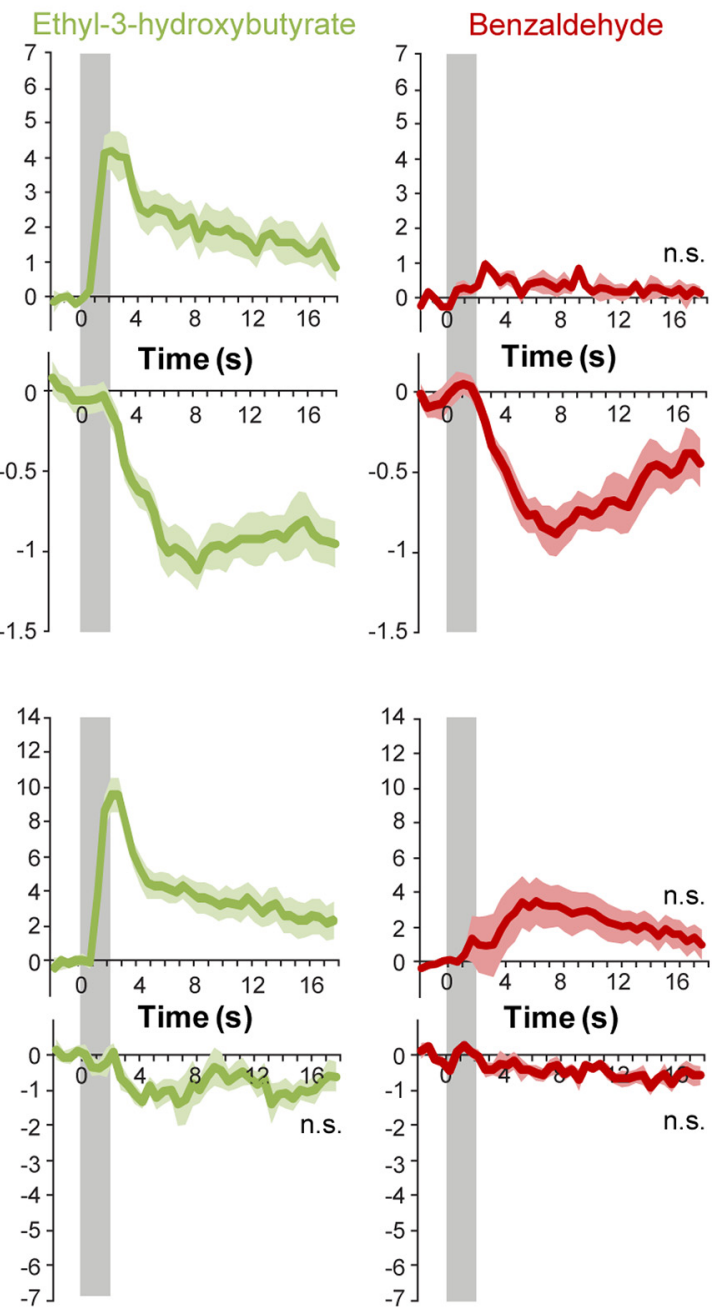

D CLOMELEON

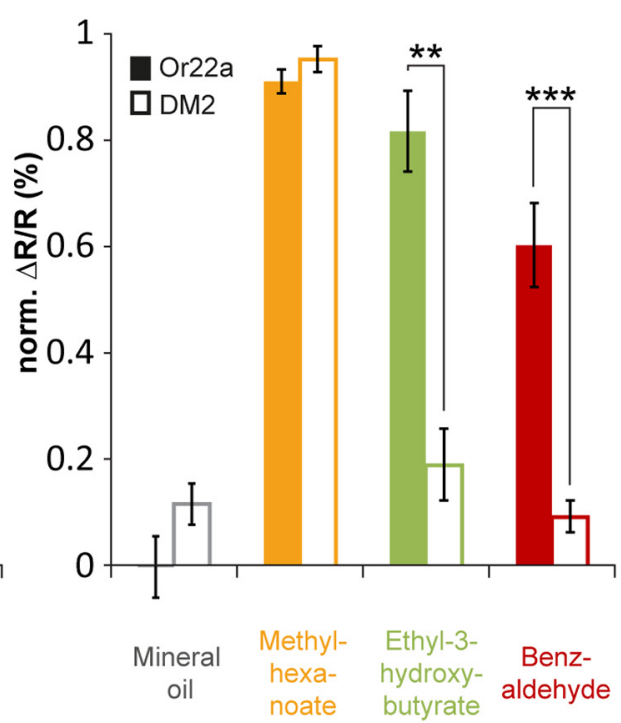

Figure 4. Chloride responses are modulated on their way from the antenna to the AL. $\boldsymbol{A}$, left, Schematic of the third antennal segment illustrating selective expression of Cameleon or Clomeleon in dendrites and somata of Or22a-expressing OSNs. Right, Averaged time courses of $\mathrm{Ca}^{2+}$ (upper row) and $\mathrm{Cl}^{-}$influx (lower row) in Or22a-expressing OSNs in the fly antenna to three different odors. Odor stimulation is indicated in gray. Lines represent means, color shadings represent SEM (n.s. not significant from solvent; $n=6-7)$. $\boldsymbol{B}$, 


\section{continued}

left, Schematic of the Drosophila AL indicating selective expression of Cameleon or Clomeleon in axonal termini of Or22a-expressing OSNs which converge to glomerulus DM2. Right, Averaged time courses of $\mathrm{Ca}^{2+}$ (upper row) and $\mathrm{Cl}^{-}$influx (lower row) in DM2 to three different odors. Odor stimulation is marked in gray. Lines represent means, color shading represents SEM $(n=6)$. C, $\boldsymbol{D}$, Quantification of $\mathrm{Ca}^{2+}(\boldsymbol{C})$ and $\mathrm{Cl}^{-}(\boldsymbol{D})$ influx in Or22a-expressing OSNs to three different odors and mineral oil. Data are shown as pair-wise comparisons between antenna (Or22a) and AL (DM2). Clomeleon and Cameleon responses have been normalized to highest $\mathrm{Cl}^{-}$or $\mathrm{Ca}^{2+}$ influx in each animal over all odors, respectively. $\mathrm{Cl}^{-}$responses to ethyl-3-hydoxybutyrate and benzaldehyde are significantly lower in the AL compared to the antenna (**p $<0.01$, ***p $<0.001$, Mann-Whitney test, $n=6-7)$.

\section{Discussion}

\section{Clomeleon-based $\mathrm{Cl}^{-}$imaging in the Drosophila nervous system}

Hardly any optical imaging technique reaches the unmatched temporal precision of electrophysiological recordings as yet, and the determination of membrane potential changes represents the most accurate approach to determine how sensory stimuli are represented by single or small groups of neurons (Wilson et al., 2004; Wilson and Laurent, 2005; Seki et al., 2017). Optical imaging, on the contrary, offers the advantage of monitoring physiologic parameters that correlate with membrane potential changes across spatiotemporally distributed populations of neurons (Ahrens et al., 2013; Chen et al., 2013). Membrane depolarization is typically accompanied by increases in intracellular $\mathrm{Ca}^{2+}$ from a variety of sources, and $\mathrm{Ca}^{2+}$ imaging represents currently the "gold standard" for visualizing neuronal excitation in Drosophila (Riemensperger et al., 2012). However, neuronal inhibition, most often mediated by $\mathrm{Cl}^{-}$influx, is not directly captured using $\mathrm{Ca}^{2+}$ imaging. Establishing Clomeleon as a tool for monitoring $\mathrm{Cl}^{-}$dynamics both in the peripheral and central nervous system provides an important step toward filling this gap. Its ratiometric nature as a FRET-based sensor demands some additional considerations in contrast to single chromophore sensors such as calcium reporters belonging to the GCaMP family (Tian et al., 2009). Especially the size, $\mathrm{pH}$ sensitivity, and slow response dynamics require the future development of a single chromophore chloride sensor, which hopefully eases its applicability. The development of the $\mathrm{Cl}^{-}$sensor SuperClomeleon, which still represents a FRET-based sensor, reveals an improved signal-to-noise ratio and needs to be established for the Drosophila olfactory system (Grimley et al., 2013).

It is important to consider that the monitored changes in intracellular $\mathrm{Ca}^{2+}$ and $\mathrm{Cl}^{-}$derive from different cell processes within the neurons. Recorded changes in $\mathrm{Ca}^{2+}$ and $\mathrm{Cl}^{-}$can therefore depend on fluxes at the synapse or along the neuron, as well as release from intracellular calcium stores, which are mediated by ligand-gated as well as voltage-gated $\mathrm{Ca}^{2+}$ and $\mathrm{Cl}^{-}$channels in insects (Messina et al., 1996; Wicher et al., 2001; Fiala and Spall, 2003; Flores et al., 2006; Pézier et al., 2010). Since the temporal resolution in functional imaging recordings is rather low compared to electrophysiological recordings, the different dynamics of these ion channels are not visible in the fluorescence signal of the different sensors.

\section{Is $\mathrm{Cl}^{-}$influx part of the olfactory signal transduction in insects?}

We observed an odor-evoked $\mathrm{Cl}^{-}$influx in OSN dendrites of the Drosophila antenna. In vertebrates, $\mathrm{Cl}^{-}$conductance is an integral component of the canonical olfactory signal transduction cascade (Labarrera et al., 2013). Here, odor stimulation leads to a membranecurrent composed of a cationic and a delayed $\mathrm{Cl}^{-}$component (Kurahashi and Yau, 1993). Although $\mathrm{Cl}^{-}$conductance is in most cases associated with neuronal inhibition, this $\mathrm{Cl}^{-}$current amplifies the olfactory signal by $\mathrm{Cl}^{-}$efflux through a $\mathrm{Ca}^{2+}$-activated $\mathrm{Cl}^{-}$channel which is most likely mediated by anoctamin-2 (ANO2; Lowe and Gold, 1993; Stephan et al., 2009; Delgado et al., 2016). The insect olfactory signal transduction is crucially different from that of vertebrates in two aspects: First, olfactory receptors of the OR and IR type are ionotropic receptors mediating excitatory cation influx (Sato et al., 2008; Wicher et al., 2008; Rytz et al., 2013). Metabotropic signaling cascades have been clearly described for insect OSNs, but their exact modulatory functions remain unclear as yet (Wicher et al., 2008). Second, the equilibrium potential of $\mathrm{Cl}^{-}\left(E_{C I}\right)$ in insect OSNs differs from that of vertebrates. Since $\left[\mathrm{Cl}^{-}\right]_{\mathrm{i}}$ is lower than in the extracellular medium, as shown in moths (Steinbrecht, 1992), the electromotive force will lead to a $\mathrm{Cl}^{-}$influx, if the membrane potential is shifted above $E_{C l}$ (i.e., $-36 \mathrm{mV}$ ). Hence, when OSNs become excited, a $\mathrm{Cl}^{-}$influx through $\mathrm{Ca}^{2+}$ activated $\mathrm{Cl}^{-}$channels might result in hyperpolarization of the plasma membrane (Pézier et al., 2010).

Interestingly, dendrites of moth OSNs express an analogous $\mathrm{Ca}^{2+}$-activated $\mathrm{Cl}^{-}$channel that functionally resembles ANO2 (Pézier et al., 2010). The Drosophila melanogaster genome contains two different ANO2 orthologues (CG6938, CG10353) whose molecular function has, however, not yet been studied. Additional experiments are needed to analyze the role of ANO2 in odor-evoked $\mathrm{Cl}^{-}$dynamics in Drosophila OSNs. The fact that the antennal $\mathrm{Cl}^{-}$influx co-occurred frequently with $\mathrm{a} \mathrm{Ca}^{2+}$ influx further suggest the existence of $\mathrm{Ca}^{2+}$-activated $\mathrm{Cl}^{-}$channels in the antenna. This type of $\mathrm{Cl}^{-}$-mediated inhibition might reflect shunting inhibition as a mechanism for gain control leading to stabilization of odorevoked excitation (Wilson and Mainen, 2006).

In addition, we also observed $\mathrm{Cl}^{-}$influx that was not directly correlated with the excitation of the respective OSNs, reflecting a second type of $\mathrm{Cl}^{-}$-mediated inhibition. This finding suggests either again the existence of $\mathrm{Cl}^{-}$channels in OSN dendrites or, alternatively, a retrograde diffusion of $\mathrm{Cl}^{-}$from the AL. Interestingly, when we abolished any feedback signaling from the $A L$, we still ob- 

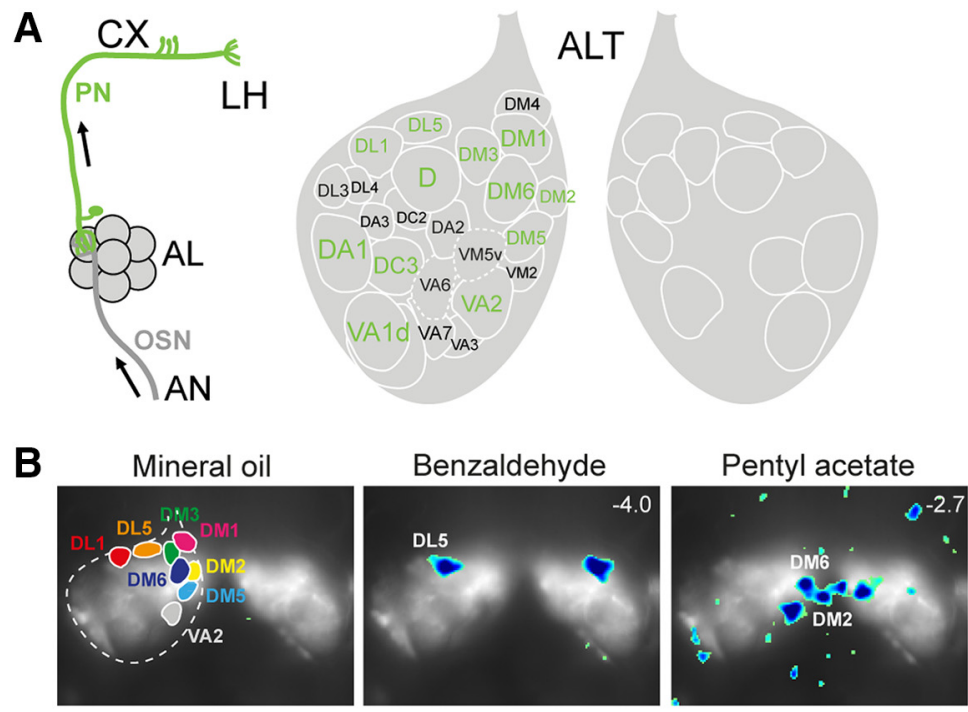

\section{Ethyl benzoate}

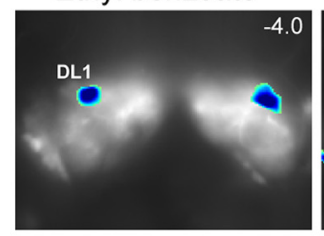

1-Hexanol

Ethyl-3-hydroxybut.
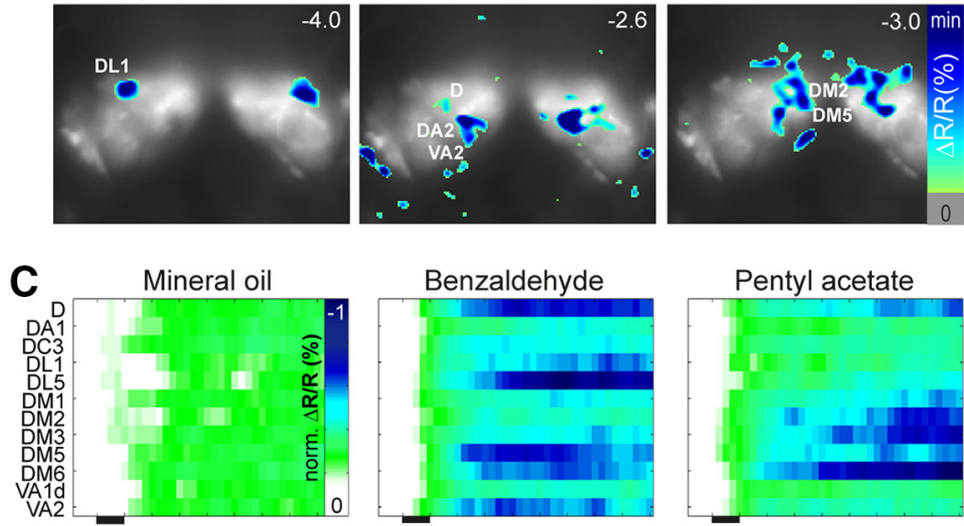

Benzaldehyde

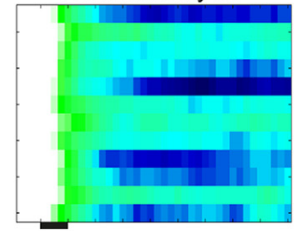

Pentyl acetate
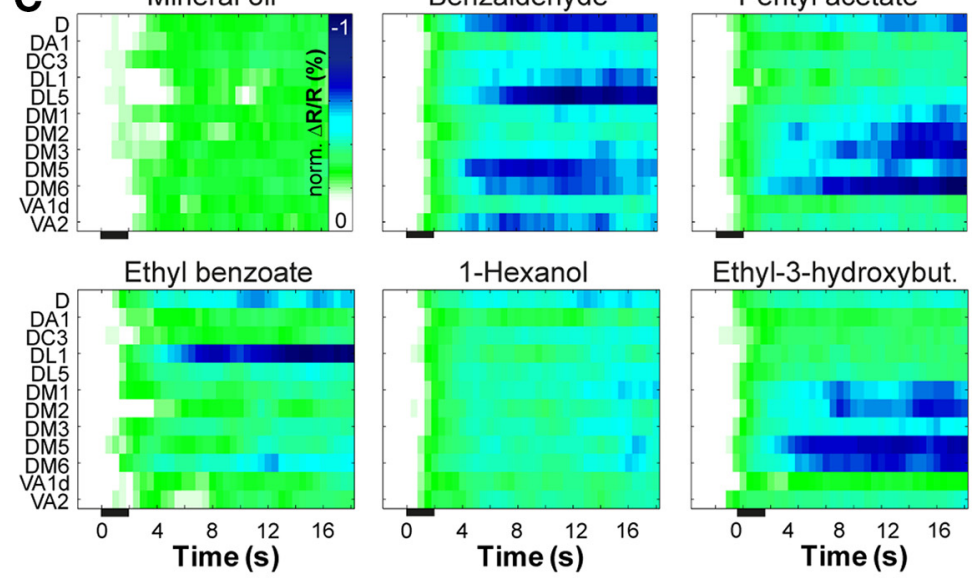

D GABA $_{A}$

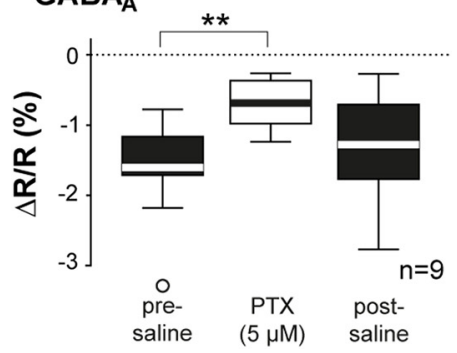

Figure 5. GABA $_{A}$ receptors contribute to odor-evoked chloride responses in PNs. $\boldsymbol{A}$, left, Schematic illustrating expression site of Clomeleon. Middle, AL map viewed from the angle that was used for imaging. Glomeruli indicated in green could reliably be identified. Right, Contralateral AL including reliably identified glomeruli. ALT, AL tract. $\boldsymbol{B}$, Pseudocolor rendering of representative $\mathrm{Cl}^{-}$responses to different odors and mineral oil in PN dendrites in the AL. Images represent $\Delta R / R(\%)$ superimposed onto raw fluorescence images according to the scale on the right. Numbers in each image give the individual fluorescence minimum. Glomerular positions are shown in the first image; individual glomeruli revealing highest $\mathrm{Cl}^{-}$increase are indicated in each image. $\boldsymbol{C}$, False color pictures of averaged odor-evoked $\mathrm{Cl}^{-}$signals for 12 identified glomeruli (40\% of all glomeruli labeled by GH146-Gal4) over time across $9-11$ animals. 
continued

Clomeleon responses were normalized to highest $\mathrm{Cl}^{-}$influx in each animal over all odors before averaging. Black bar indicates the odor application. $\boldsymbol{D}$, Quantification of $\mathrm{Cl}^{-}$influx to ethyl-3-hydroxybutyrate in PNs before, during and after applying of picrotoxin. The $\mathrm{GABA}_{\mathrm{A}}$ receptor blocker significantly reduces odor-evoked $\mathrm{Cl}^{-}$responses $(* * p<0.01$, repeated measures ANOVA, $n=9)$.

served $\mathrm{Cl}^{-}$influx, supporting the first assumption. However, since the $\mathrm{Cl}^{-}$signals were not identical but reduced, we assume that $\mathrm{Cl}^{-}$dynamics in OSN dendrites are partly influenced by $\mathrm{Cl}^{-}$influx into OSN axonal termini in the AL. The latter assumption is further supported by our observation that applying GABA to the AL induced a significant $\mathrm{Cl}^{-}$influx in the antenna (data not shown).

The comprehensive study by Hallem and Carlson on receptor-ligand interactions where a widespread inhibition below baseline firing rates among one third out of 24 selectively expressed ORs was observed (Hallem and Carlson, 2006), is well in line with our observation of inhibitory odor responses in the Drosophila antenna. Interestingly, OSNs expressing Or47b, known to selectively respond to the pheromone methyl laurate (Dweck et al., 2015), were never excited by the large odor set tested in the aforementioned study, but showed inhibitory responses to $34 \%$ of the odors. Those OSNs target glomerulus VA1d, and we indeed observed clear odor-evoked $\mathrm{Cl}^{-}$responses in VA1d, while $\mathrm{Ca}^{2+}$-influx did never occur. In addition, $\mathrm{Cl}^{-}$imaging of Or47b-expressing OSNs on the antenna confirms the odor-induced inhibition of this OSN type. As a second example, benzaldehyde elicited a strong $\mathrm{Cl}^{-}$influx in OSNs expressing Or22a in the antenna without being accompanied by a $\mathrm{Ca}^{2+}$ influx. This odor has already been characterized as an Or22a-inhibitor (Pelz et al., 2006; Wicher et al., 2008), which strongly suggests that our second type of $\mathrm{Cl}^{-}$-mediated inhibition reflects hyperpolarization and thus odor-specific inhibition in the antenna. Therefore, our study demonstrates that inhibitory odor responses of OSNs are not only generated by a reduction in the intracellular cation concentration leading to a reduced firing rate as widely assumed, but that they are also carried by an influx of $\mathrm{Cl}^{-}$. It still remains to be investigated how $\mathrm{Cl}^{-}$channels are integrated in the olfactory signal transduction machinery of insects.

\section{Multiple roles of $\mathrm{Cl}^{-}$signaling at the $\mathrm{AL}$ network level}

Within the insect $A L$, odor representations are shaped by the inhibitory network of various types of GABAergic LNs (Sachse and Galizia, 2002; Wilson and Laurent, 2005; Silbering and Galizia, 2007; Hong and Wilson, 2015; Mohamed et al., 2019). It has been shown that OSNs are presynaptically inhibited by LNs, mediated by both $\mathrm{GABA}_{A}$ and $\mathrm{GABA}_{B}$ receptors (Olsen and Wilson, 2008; Root et al., 2008). Since $\mathrm{GABA}_{\mathrm{A}}$ receptors are ligandactivated $\mathrm{Cl}^{-}$channels, they provide a direct molecular substrate for the $\mathrm{Cl}^{-}$influx in OSNs at the $\mathrm{AL}$ level. Likewise, PNs express both $\mathrm{GABA}_{A}$ and $\mathrm{GABA}_{B}$ receptors (Enell et al., 2007), and their odor responses are influenced by both receptor types (Wilson and Laurent, 2005; Silbering and Galizia, 2007). Here we confirm the contribution of $\mathrm{GABA}_{\mathrm{A}}$ receptors pharmacologically for $\mathrm{Cl}^{-}$influx. In addition, our data provide evidence that the synaptic inhibition of PNs is stronger than that of OSNs, since we clearly see an increase in the number of inhibited glomeruli from the input to the output level. However, one has to keep in mind that the sensor dynamics might not reflect the potentially varying dynamics of the membrane potential in these different neuron types. Chloride ions themselves have their own dynamics, and potentially those dynamics reflect actual neuronal dynamics only loosely. Still, our data demonstrates a transformation of odor representations that is not accessible if only excitation-associated $\mathrm{Ca}^{2+}$ is taken into account. Our findings suggest two distinct types of $\mathrm{Cl}^{-}$signals in the $\mathrm{AL}$, i.e., a global, moderate inhibition and a strong, cell-typespecific inhibition. This reflects the structural diversity of GABAergic LNs in the Drosophila AL (Chou et al., 2010; Seki et al., 2010; Hong and Wilson, 2015). The majority of LNs arborizes in most glomeruli, and therefore evenly distributes the input from most OSN types. Thus, we would expect that the level of inhibition in each glomerulus should mirror the level of activity in all glomeruli with varying sensitivities to the GABAergic input (Hong and Wilson, 2015). This assumption provides a mechanism for global, inhibitory gain control at the cellular and network level to keep the olfactory circuitry in the operating state across odorant combinations and concentrations as shown for the zebrafish olfactory bulb (Zhu et al., 2013).

As a second type of $\mathrm{Cl}^{-}$-mediated inhibition, we observed $\mathrm{Cl}^{-}$responses that were not linked to any excitation, and most likely reflect local inhibition that specifically shapes neuronal information processing, analogous to the mammalian system (Mori et al., 1999; Urban, 2002). In fact, heterogeneous populations of LNs innervating only few glomeruli also exist (Chou et al., 2010; Seki et al., 2010), which might provide the neuronal substrate for such glomerulus- and odor-specific inhibition. Along that line, recent data provide evidence that patchy, but not global GABAergic LNs accomplish selective lateral inhibition between specific glomeruli processing odors with opposing hedonic valences (Mohamed et al., 2019).

\section{Temporal aspects of odor-evoked chloride responses}

The measured odor-induced $\mathrm{Cl}^{-}$and $\mathrm{Ca}^{2+}$ responses reveal different temporal dynamics. However, the temporal differences between $\mathrm{Ca}^{2+}$ - and $\mathrm{Cl}^{-}$-evoked signals are difficult to interpret because it is not clear whether they derive from different reporter dynamics or indeed reflect physiologic properties. Hence when considering temporal dynamics, we restricted any comparison of data obtained to only one reporter protein and therefore compared dynamics of input and output neurons for Cameleon and Clomeleon separately.

Although the chloride influx is clearly odor-induced, it evolves slowly over time and outlasts the odor stimulation period. Such long-lasting chloride responses are consis- 
A

Olfactory

sensory

(OSN)

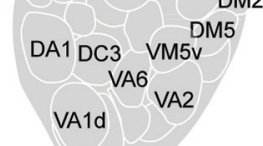

neuron $\mathrm{DL} 3$
B

Projection

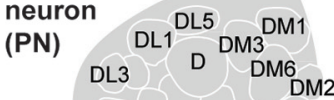

DA1 DC3 DM5
VA1d VA2
ALT

ON CAMELEON
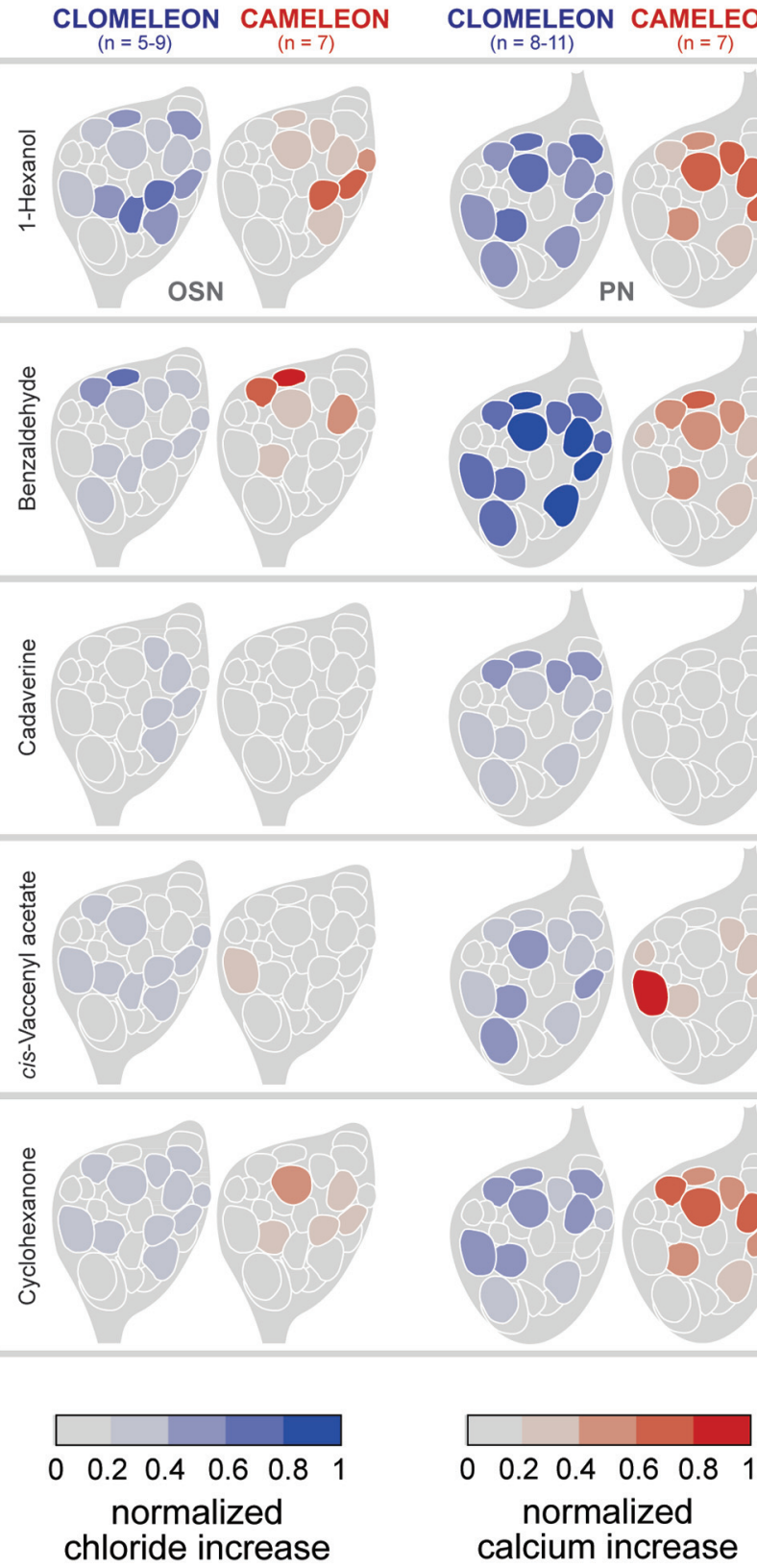

PN

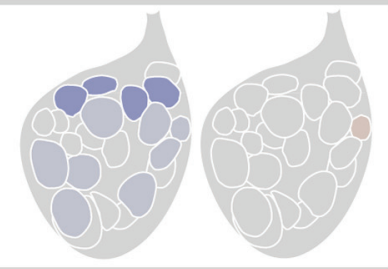

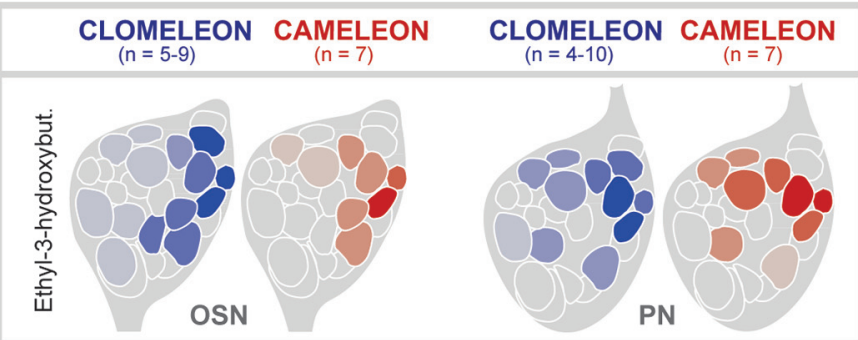
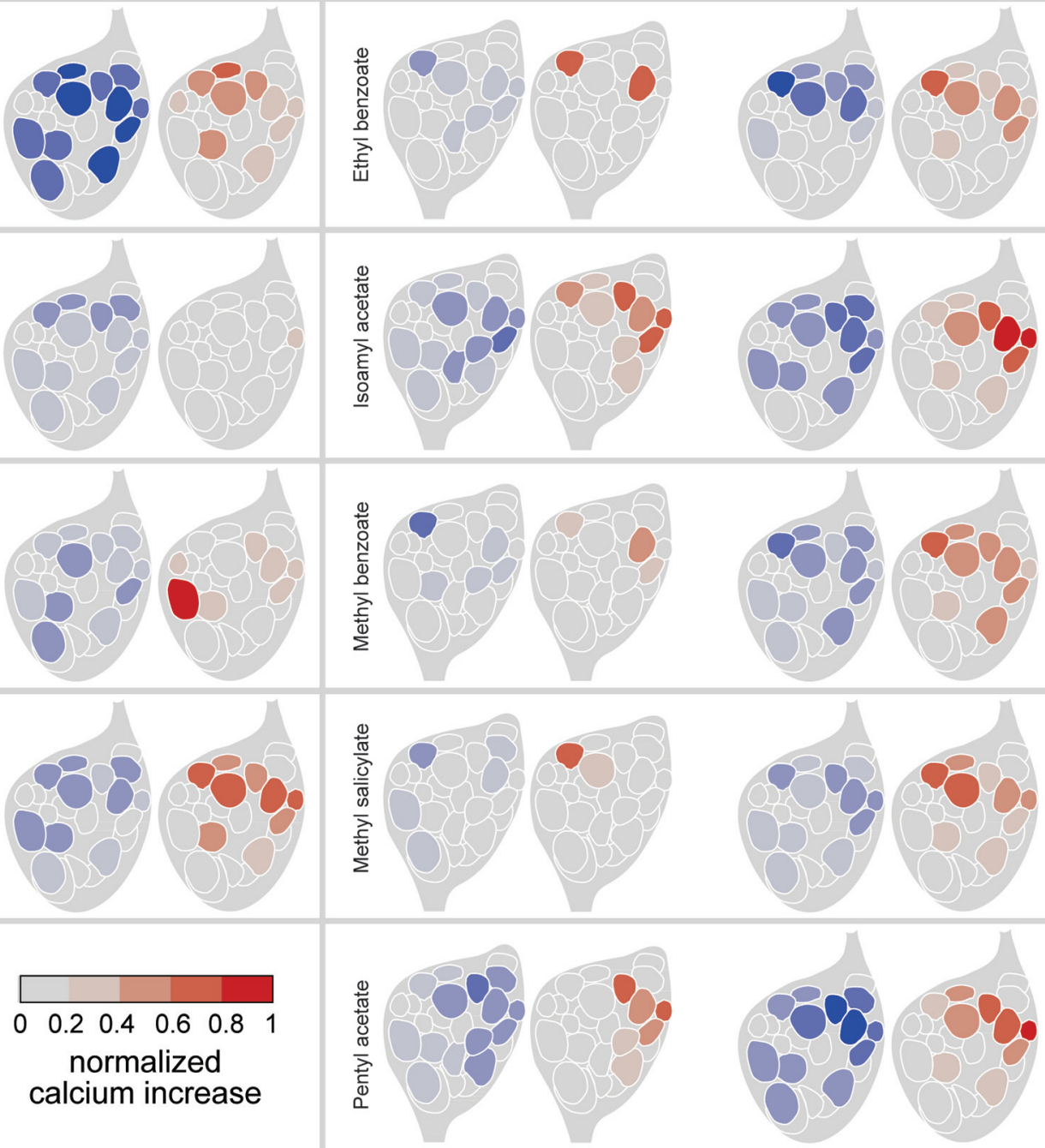

Figure 6. A functional map of odor-evoked inhibition and excitation. $\boldsymbol{A}, \boldsymbol{B}$, Averaged odor-evoked $\mathrm{Cl}^{-}$(left, in blue) and $\mathrm{Ca}^{2+}$ (right, in red) responses in OSNs $(\boldsymbol{A})$ and PNs $(\boldsymbol{B})$ are represented as schematic ALs for 11 odors according to the scales below. Responses were normalized to highest $\mathrm{Cl}^{-}$or $\mathrm{Ca}^{2+}$ influx in each animal over all odors. Glomerular identities are indicated by $\mathrm{AL}$ maps at the top. $\mathrm{AC}$, antennal commissure; $\mathrm{AN}$, antennal nerve; $\mathrm{ALT}, \mathrm{AL}$ tract. 



1-Hexanol Ethyl-3-hydrox. Ethyl benzoate

Figure 7. Input-output transformation of odor-evoked $\mathrm{Ca}^{2+}$ and $\mathrm{Cl}^{-}$responses. $\boldsymbol{A}$, False colored activity of averaged odor-evoked 
continued

$\mathrm{Ca}^{2+}$ (white-yellow-red) and $\mathrm{Cl}^{-}$(white-green-blue) influx to different odors for the same set of glomeruli in OSNs (upper panels) and PNs (lower panels) over time. Responses were normalized to highest $\mathrm{Cl}^{-}$or $\mathrm{Ca}^{2+}$ influx in each animal over all odors before averaging. Black bars indicate odor application. $\boldsymbol{B}$, Time courses of mean excitation (above, red) and inhibition (below, blue) to different odors averaged over all glomeruli and animals for OSNs (solid line) and PNs (dotted line). Odor stimulation is given by a gray bar. Cameleon, $n=7$; Clomeleon, $n=9-11$. C, Odor separation visualized using principal component analysis. The first three principal components account for 67.3\% (OSNs: Cameleon), 67.4\% (OSNs: Clomeleon), 79.7\% (PNs: Cameleon), and 59\% (PNs: Clomeleon) of the variation in the related data set. Plotting the first three principal components reveals odor-specific trajectories of ensemble activity in OSNs (upper panels) and PNs (lower panels). D, upper two panels, Time-resolved Euclidean distances (ED) between population vectors of different odor representations using Cameleon. Odor stimulation is marked in gray. Distances were calculated separately for OSN (solid lines) and PN (dotted lines) responses. Individual pair-wise odor distances are given by thin lines, averaged Euclidean distances are shown in bold. Lower panel, Latency to half maximal odor separation based on normalized Euclidean distances for 10 pair-wise odor combinations (individual lines in $\boldsymbol{B}$ ) for $\mathrm{Ca}^{2+}$ signals in OSNs and PNs. PNs reach half maximum odor separation significantly earlier than OSNs (***p $<0.001$, two-tailed paired $t$ test; $n=7$ ). $\boldsymbol{E}$, Same as in $\boldsymbol{D}$ for Clomeleon-derived odor responses. Half maximum odor separation based on odor-evoked $\mathrm{Cl}^{-}$responses occurs significantly earlier in PNs than in OSNs $(* p<0.05$, two-tailed paired $t$ test; $n=9-11)$.

tent with observations in mammalian neurons (Kuner and Augustine, 2000; Berglund et al., 2006) and might reflect the relatively slow rate of $\mathrm{Cl}^{-}$removal from the neurons (Staley and Proctor, 1999; Berglund et al., 2009, 2016). This slow recovery in the $\mathrm{Cl}^{-}$response might affect the excitability of the neuron for a period significantly outlasting the stimulation. However, as mentioned above, the kinetics of fluorescence sensors depend on intrinsic parameters of the sensor itself and firm conclusions about the exact kinetics about the $\mathrm{Cl}^{-}$currents cannot be drawn as yet.

\section{Determining $\mathrm{Cl}^{-}$and $\mathrm{Ca}^{2+}$ representations together provide a more accurate assessment of sensory processing}

The importance of synaptic inhibition for accurate behavioral responses to olfactory stimuli has been demonstrated in different species. Mice show accelerated discrimination ability when synaptic inhibition of mitral cells is increased by selectively altering granule cell function (Abraham et al., 2010). In locusts and flies, disruptive manipulation of the GABAergic AL network reduces the insects' ability to behaviorally discriminate between similar odors (Stopfer et al., 1997; Barth et al., 2014). The similarity between glomerular excitation patterns evoked by different odors often matches with the animals' ability to discriminate between the odors in behavioral tasks (Sachse and Galizia, 2003; Guerrieri et al., 2005; Niewalda et al., 2011; Barth et al., 2014; Carcaud et al., 2018). In Drosophila, the spatiotemporal, glomerular $\mathrm{Ca}^{2+}$ activity patterns at the PN level reflect more accurately the animals' perception of similarities between odors than the patterns observed at the OSN level (Niewalda et al., 2011). This difference between OSNs and PNs could, at least partly, be due to the influence of GABA-mediated inhibition. Determining $\mathrm{Cl}^{-}$-mediated inhibition across ensembles of neurons in addition to $\mathrm{Ca}^{2+}$-mediated excitation therefore enables us to more comprehensively and more accurately characterize sensory processing underlying the perception of olfactory or other sensory stimuli.

\section{References}

Abraham NM, Egger V, Shimshek DR, Renden R, Fukunaga I, Sprengel R, Seeburg PH, Klugmann M, Margrie TW, Schaefer AT, Kuner
T (2010) Synaptic inhibition in the olfactory bulb accelerates odor discrimination in mice. Neuron 65:399-411.

Abuin L, Bargeton B, Ulbrich MH, Isacoff EY, Kellenberger S, Benton $R$ (2011) Functional architecture of olfactory ionotropic glutamate receptors. Neuron 69:44-60.

Ahrens MB, Orger MB, Robson DN, Li JM, Keller PJ (2013) Wholebrain functional imaging at cellular resolution using light-sheet microscopy. Nat Methods 10:413.

Barth J, Dipt S, Pech U, Hermann M, Riemensperger T, Fiala A (2014) Differential associative training enhances olfactory acuity in Drosophila melanogaster. J Neurosci 34:1819-1837.

Berglund K, Kuner T, Augustine GJ (2009) Clomeleon, a genetically encoded chloride indicator. In: Physiology and pathology of chloride transporters and channels in the nervous system (Alvarez $M$, ed), pp 123-136. San Diego: Academis Press.

Berglund K, Schleich W, Krieger P, Loo L, Wang D, Cant N, Feng G, Augustine G, Kuner T (2006) Imaging synaptic inhibition in transgenic mice expressing the chloride indicator, clomeleon. Brain Cell Biol 35:207-228.

Berglund K, Wen L, Dunbar RL, Feng G, Augustine GJ (2016) Optogenetic visualization of presynaptic tonic inhibition of cerebellar parallel fibers. J Neurosci 36:5709-5723.

Bhandawat V, Olsen SR, Gouwens NW, Schlief ML, Wilson RI (2007) Sensory processing in the Drosophila antennal lobe increases reliability and separability of ensemble odor representations. Nat Neurosci 10:1474-1482.

Brand AH, Perrimon N (1993) Targeted gene expression as a means of altering cell fates and generating dominant phenotypes. Development 118:401-415.

Carcaud J, Giurfa M, Sandoz J-C (2018) Differential processing by two olfactory subsystems in the honeybee brain. Neuroscience 374:33-48.

Chen TW, Wardill TJ, Sun Y, Pulver SR, Renninger SL, Baohan A, Schreiter ER, Kerr RA, Orger MB, Jayaraman V, Looger LL, Svoboda K, Kim DS (2013) Ultrasensitive fluorescent proteins for imaging neuronal activity. Nature 499:295.

Chou YH, Spletter ML, Yaksi E, Leong JCS, Wilson RI, Luo L (2010) Diversity and wiring variability of olfactory local interneurons in the Drosophila antennal lobe. Nat Neurosci 13:439-449.

Couto A, Alenius M, Dickson BJ (2005) Molecular, anatomical, and functional organization of the Drosophila olfactory system. Curr Biol 15:1535-1547.

Delgado R, Mura CV, Bacigalupo J (2016) Single $\mathrm{Ca}^{2+}$-activated $\mathrm{Cl}^{-}$ channel currents recorded from toad olfactory cilia. BMC Neurosci 17:17.

Duebel J, Haverkamp S, Schleich W, Feng G, Augustine GJ, Kuner T, Euler T (2006) Two-photon imaging reveals somatodendritic chloride gradient in retinal ON-type bipolar cells expressing the biosensor clomeleon. Neuron 49:81-94. 
Dweck HKM, Ebrahim SAM, Thoma M, Mohamed AAM, Keesey IW, Trona F, Lavista-Llanos S, Svatoš A, Sachse S, Knaden M, Hansson BS (2015) Pheromones mediating copulation and attraction in Drosophila. Proc Natl Acad Sci USA 112:E2829-E2835.

Egger V, Urban NN (2006) Dynamic connectivity in the mitral cellgranule cell microcircuit. Semin Cell Dev Biol 17:424-432.

Enell L, Hamasaka Y, Kolodziejczyk A, Nässel DR (2007) $\gamma$-Aminobutyric acid (GABA) signaling components in Drosophila: immunocytochemical localization of GABAB receptors in relation to the GABAA receptor subunit RDL and a vesicular GABA transporter. J Comp Neurol 505:18-31.

Fiala A, Spall T (2003) In vivo calcium imaging of brain activity in Drosophila by transgenic cameleon expression. Sci STKE 2003: PL6.

Fiala A, Spall T, Diegelmann S, Eisermann B, Sachse S, Devaud JM, Buchner E, Galizia CG (2002) Genetically expressed cameleon in Drosophila melanogaster is used to visualize olfactory information in projection neurons. Curr Biol 12:1877-1884.

Fishilevich E, Vosshall LB (2005) Genetic and functional subdivision of the Drosophila antennal lobe. Curr Biol 15:1548-1553.

Flores CA, Niemeyer MI, Sepúlveda FV, Cid LP (2006) Two splice variants derived from a Drosophila melanogaster candidate CIC gene generate $\mathrm{ClC}-2$-type $\mathrm{Cl}$ - channels. Mol Membr Biol 23:149156.

Glykys J, Dzhala VI, Kuchibhotla KV, Feng G, Kuner T, Augustine G, Bacskai BJ, Staley KJ (2009) Differences in cortical versus subcortical GABAergic signaling: a candidate mechanism of electroclinical uncoupling of neonatal seizures. Neuron 63:657-672.

Grabe V, Strutz A, Baschwitz A, Hansson BS, Sachse S (2015) Digital in vivo $3 \mathrm{D}$ atlas of the antennal lobe of Drosophila melanogaster. J Comp Neurol 523:530-544.

Grabe V, Baschwitz A, Dweck Hany KM, Lavista-Llanos S, Hansson Bill S, Sachse S (2016) Elucidating the neuronal architecture of olfactory glomeruli in the Drosophila antennal lobe. Cell Rep 16: 3401-3413.

Grienberger C, Konnerth A (2012) Imaging calcium in neurons. Neuron 73:862-885.

Grimley JS, Li L, Wang W, Wen L, Beese LS, Hellinga HW, Augustine GJ (2013) Visualization of synaptic inhibition with an optogenetic sensor developed by cell-free protein engineering automation. $J$ Neurosci 33:16297-16309.

Guerrieri F, Schubert M, Sandoz JC, Giurfa M (2005) Perceptual and neural olfactory similarity in honeybees. PLoS Biol 3:e60.

Hallem EA, Carlson JR (2006) Coding of odors by a receptor repertoire. Cell 125:143-160.

Haverkamp S, Wässle H, Duebel J, Kuner T, Augustine GJ, Feng G, Euler T (2005) The primordial, blue-cone color system of the mouse retina. J Neurosci 25:5438-5445.

Hong J, Wilson I (2015) Simultaneous encoding of odors by channels with diverse sensitivity to inhibition. Neuron 85:573-589.

Knaden M, Strutz A, Ahsan J, Sachse S, Hansson BS (2012) Spatial representation of odorant valence in an insect brain. Cell Rep 1:392-399.

Kuner T, Augustine GJ (2000) A genetically encoded ratiometric indicator for chloride: capturing chloride transients in cultured hippocampal neurons. Neuron 27:447-459.

Kurahashi T, Yau KW (1993) Co-existence of cationic and chloride components in odorant-induced current of vertebrate olfactory receptor cells. Nature 363:71-74.

Labarrera C, London M, Angelo K (2013) Tonic inhibition sets the state of excitability in olfactory bulb granule cells. J Physiol 591: $1841-1850$

Laissue PP, Reiter C, Hiesinger PR, Halter S, Fischbach KF, Stocker RF (1999) Three-dimensional reconstruction of the antennal lobe in Drosophila melanogaster. J Comp Neurol 405:543-552.

Laurent G, Stopfer M, Friedrich RW, Rabinovich MI, Volkovskii A, Abarbanel HDI (2001) Odor encoding as an active, dynamical process: experiments, computation and theory. Annu Rev Neurosci 24:263-297.
Liu WW, Wilson RI (2013) Glutamate is an inhibitory neurotransmitter in the Drosophila olfactory system. Proc Natl Acad Sci USA 110: 10294-10299.

Lowe G, Gold GH (1993) Nonlinear amplification by calciumdependent chloride channels in olfactory receptor cells. Nature 366:283-286.

Margrie TW, Schaefer AT (2003) Theta oscillation coupled spike latencies yield computational vigour in a mammalian sensory system. J Physiol 546:363-374.

Martelli C, Fiala A (2019) Slow presynaptic mechanisms that mediate adaptation in the olfactory pathway of Drosophila. Elife 8:e43735.

Messina A, Neri M, Perosa F, Caggese C, Marino M, Caizzi R, De Pinto V (1996) Cloning and chromosomal localization of a cDNA encoding a mitochondrial porin from Drosophila melanogaster. FEBS Lett 384:9-13.

Miyawaki A, Griesbeck O, Heim R, Tsien RY (1999) Dynamic and quantitative $\mathrm{Ca} 2+$ measurements using improved cameleons. Proc Natl Acad Sci USA 96:2135-2140.

Mohamed AAM, Retzke T, Das Chakraborty S, Fabian B, Hansson BS, Knaden M, Sachse S (2019) Odor mixtures of opposing valence unveil inter-glomerular crosstalk in the Drosophila antennal lobe. Nat Commun 10:1201.

Mori K, Nagao H, Yoshihara Y (1999) The olfactory bulb: coding and processing of odor molecule information. Science 286:711-715.

Nagel KI, Hong EJ, Wilson RI (2015) Synaptic and circuit mechanisms promoting broadband transmission of olfactory stimulus dynamics. Nat Neurosci 18:56.

Niewalda T, Völler T, Eschbach C, Ehmer J, Chou W-C, Timme M, Fiala A, Gerber B (2011) A combined perceptual, physicochemical, and imaging approach to 'odour-distances' suggests a categorizing function of the Drosophila antennal lobe. PLoS One 6:e24300

O'Donnell MJ, Rheault MR, Davies SA, Rosay P, Harvey BJ, Maddrell SHP, Kaiser K, Dow JAT (1998) Hormonally controlled chloride movement across Drosophila tubules is via ion channels in stellate cells. Am J Physiol 274:R1039-R1049.

Olsen SR, Wilson RI (2008) Lateral presynaptic inhibition mediates gain control in an olfactory circuit. Nature 452:956-960.

Owens DF, Kriegstein AR (2002) Is there more to GABA than synaptic inhibition? Nat Rev Neurosci 3:715-727.

Pelz D, Roeske T, Syed Z, Bruyne M, Galizia CG (2006) The molecular receptive range of an olfactory receptor in vivo (Drosophila melanogaster Or22a). J Neurobiol 66:1544-1563.

Pézier A, Grauso M, Acquistapace A, Monsempes C, Rospars J-P, Lucas P (2010) Calcium activates a chloride conductance likely involved in olfactory receptor neuron repolarization in the moth Spodoptera littoralis. J Neurosci 30:6323-6333.

Reinert A, Barapatre N, Sachse S, Reinert T (2011) $\mu$ PIXE for a $\mu$ Brain: the vinegar fly's brain, antenna, sensilla hairs and eye ion concentrations. Nucl Instrum Methods Phys Res B 269:22922296.

Riemensperger T, Pech U, Dipt S, Fiala A (2012) Optical calcium imaging in the nervous system of Drosophila melanogaster. Biochim Biophys Acta 1820:1169-1178.

Root CM, Masuyama K, Green DS, Enell LE, Nässel DR, Lee C-H, Wang JW (2008) A presynaptic gain control mechanism fine-tunes olfactory behavior. Neuron 59:311-321.

Rytz R, Croset V, Benton R (2013) lonotropic receptors (IRs): chemosensory ionotropic glutamate receptors in Drosophila and beyond. Insect Biochem Mol Biol 43:888-897.

Sachse S, Galizia CG (2002) Role of inhibition for temporal and spatial odor representation in olfactory output neurons: a calcium imaging study. J Neurophysiol 87:1106-1117.

Sachse S, Galizia CG (2003) The coding of odour-intensity in the honeybee antennal lobe: local computation optimizes odour representation. Eur J Neurosci 18:2119-2132.

Sato K, Pellegrino M, Nakagawa T, Nakagawa T, Vosshall LB, Touhara K (2008) Insect olfactory receptors are heteromeric ligandgated ion channels. Nature 452:1002. 
Schoppa NE, Westbrook GL (1999) Regulation of synaptic timing in the olfactory bulb by an A-type potassium current. Nat Neurosci 2:1106-1113

Schoppa NE, Urban NN (2003) Dendritic processing within olfactory bulb circuits. Trends Neurosci 26:501-506.

Schubert M, Hansson BS, Sachse S (2014) The banana code natural blend processing in the olfactory circuitry of Drosophila melanogaster. Front Physiol 5:59.

Seki Y, Rybak J, Wicher D, Sachse S, Hansson BS (2010) Physiological and morphological characterization of local interneurons in the Drosophila antennal lobe. J Neurophysiol 104:1007-1019.

Seki Y, Dweck HKM, Rybak J, Wicher D, Sachse S, Hansson BS (2017) Olfactory coding from the periphery to higher brain centers in the Drosophila brain. BMC Biol 15:56.

Shanbhag SR, Müller B, Steinbrecht RA (1999) Atlas of olfactory organs of Drosophila melanogaster: 1. Types, external organization, innervation and distribution of olfactory sensilla. Int J Insect Morphol Embryol 28:377-397.

Silbering AF, Galizia CG (2007) Processing of odor mixtures in the Drosophila antennal lobe reveals both global inhibition and glomerulus-specific interactions. J Neurosci 27:11966-11977.

Staley KJ, Proctor WR (1999) Modulation of mammalian dendritic $\mathrm{GABA}(\mathrm{A})$ receptor function by the kinetics of $\mathrm{Cl}-$ and $\mathrm{HCO} 3-$ transport. J Physiol 519:693-712.

Steinbrecht RA (1992) Experimental morphology of insect olfaction: tracer studies, x-ray microanalysis, autoradiography, and immunocytochemistry with silkmoth antennae. Micros Res Tech 22: 336-350.

Stephan AB, Shum EY, Hirsh S, Cygnar KD, Reisert J, Zhao H (2009) ANO2 is the cilial calcium-activated chloride channel that may mediate olfactory amplification. Proc Natl Acad Sci USA 106: 11776-11781.

Stocker RF, Heimbeck G, Gendre N, de Belle JS (1997) Neuroblast ablation in Drosophila P[GAL4] lines reveals origins of olfactory interneurons. J Neurobiol 32:443-456.
Stopfer M, Bhagavan S, Smith BH, Laurent G (1997) Impaired odour discrimination on desynchronization of odour-encoding neural assemblies. Nature 390:70-74.

Strutz A, Voeller T, Riemensperger T, Fiala A, Sachse S (2012) Calcium imaging of neural activity in the olfactory system of Drosophila. In: Genetically encoded functional indicators (Martin JR, ed), pp 43-70. New York: Springer Science+Business Media, LLC.

Tian L, Hires SA, Mao T, Huber D, Chiappe ME, Chalasani SH, Petreanu L, Akerboom J, McKinney SA, Schreiter ER, Bargmann Cl, Jayaraman V, Svoboda K, Looger LL (2009) Imaging neural activity in worms, flies and mice with improved GCaMP calcium indicators. Nat Meth 6:875-881.

Urban NN (2002) Lateral inhibition in the olfactory bulb and in olfaction. Physiol Behav 77:607-612.

Vosshall LB, Wong AM, Axel R (2000) An olfactory sensory map in the fly brain. Cell 102:147-159.

Wang JW, Wong AM, Flores J, Vosshall LB, Axel R (2003) Twophoton calcium imaging reveals an odor-evoked map of activity in the fly brain. Cell 112:271-282.

Wicher D, Walther C, Wicher C (2001) Non-synaptic ion channels in insects - basic properties of currents and their modulation in neurons and skeletal muscles. Prog Neurobiol 64:431-525.

Wicher D, Schäfer R, Bauernfeind R, Stensmyr MC, Heller R, Heinemann SH, Hansson BS (2008) Drosophila odorant receptors are both ligand-gated and cyclic-nucleotide-activated cation channels. Nature 452:1007-1011.

Wilson RI, Laurent G (2005) Role of GABAergic inhibition in shaping odor-evoked spatiotemporal patterns in the Drosophila antennal lobe. J Neurosci 25:9069-9079.

Wilson RI, Mainen ZF (2006) Early events in olfactory processing. Annu Rev Neurosci 29:163-201.

Wilson RI, Turner GC, Laurent G (2004) Transformation of olfactory representations in the Drosophila antennal lobe. Science 303:366-370.

Zhu P, Frank T, Friedrich RW (2013) Equalization of odor representations by a network of electrically coupled inhibitory interneurons. Nat Neurosci 16:1678. 